\title{
Enhancement of Polymer Cytocompatibility by Nanostructuring of Polymer Surface
}

\author{
Petr Slepička, ${ }^{1}$ Nikola Slepičková Kasálková, ${ }^{1}$ Lucie Bačáková, ${ }^{2}$ \\ Zdeňka Kolská, ${ }^{3}$ and Václav Švorčík ${ }^{1}$ \\ ${ }^{1}$ Department of Solid State Engineering, Institute of Chemical Technology, 16628 Prague, Czech Republic \\ ${ }^{2}$ Institute of Physiology, Academy of Sciences of The Czech Republic, 14220 Prague, Czech Republic \\ ${ }^{3}$ Faculty of Science, Jan Evangelista Purkynè University, 40096 Ústí nad Labem, Czech Republic
}

Correspondence should be addressed to Petr Slepička, petr.slepicka@vscht.cz

Received 14 March 2012; Accepted 5 June 2012

Academic Editor: Shafiul Chowdhury

Copyright () 2012 Petr Slepička et al. This is an open access article distributed under the Creative Commons Attribution License, which permits unrestricted use, distribution, and reproduction in any medium, provided the original work is properly cited.

\begin{abstract}
Polymers with their advantageous physical, chemical, mechanical, and electrical properties and easy manufacturing are widely used in biology, tissue engineering, and medicine, for example, as prosthetic materials. In some cases the polymer usage may be impeded by low biocompatibility of common synthetic polymers. The biocompatibility can be improved by modification of polymer surface, for example, by plasma discharge, irradiation with ionizing radiation, and sometime subsequent grafting with suitable organic (e.g., amino-acids) or inorganic (e.g., gold nanoparticles) agents. In this way new chemically active structures are created on the polymer surface, and in some cases new surface relief is created. Recent advances in nanotechnology and in characterization of nanostructured objects open the way to development of new polymer-based materials with better bioproperties and higher application potential in biomedicine. Some of recent results obtained in the field are summarized and discussed in this paper.
\end{abstract}

\section{Introduction}

Effective interaction of living cells with polymer-based substrates is main prerequisite of their successful application in biology, biotechnology, and medicine. It is well known that polymer surface chemistry and surface topography strongly influence cell functions, cell adhesion, and proliferation [1]. Cells attach to the polymer surface via focal adhesion points, connecting the cytoskeleton to the polymer surface. Formation of these interfaces is affected not only by the surface chemistry (e.g., presence of ligands), electrostatic charge, wettability (surface polarity), and elastic modulus $[2,3]$ but also by the surface topography which can affect cell alignment and their migration or outgrowth along a specific orientation $[4,5]$. Surface nanopatterning can be achieved also by methods such as lithographic methods including soft-lithography, dip pen, template, self-assembly, selective etching, and selective chemical methods [3], which can be used for nanopatterning of polymer surfaces. Biomaterials, based on various polymers, are also used extensively in pharmaceutical industry, tissue engineering, or food processing. Contemporary research is focused on design and preparation of biomaterials suitable for optimal cell organization, proliferation, and tissue growth. Nanotechnology, dealing with objects or systems with typical dimensions below $100 \mathrm{~nm}$, opens new prospectives in the field. The transition in characteristic size of the objects from microto nanometer scale significantly changes physicochemical, mechanical, optical, and electrical properties of materials, which could be used for preparation of new, more convenient materials for biology, biotechnology, tissue engineering, and medicine. In this work some of the recent results obtained in the field are summarized and discussed.

\section{Modification of Polymer Surface}

Physicochemical properties of polymer surface may be modified by many techniques based on various chemical or physical processes. Modification by direct chemical reaction 
may be accomplished by, for example, alkaline or acid etching, oxidation (e.g., via $\mathrm{O}_{3}$ ), and several other chemical mechanisms [12]. Among physical methods an important technique is deposition of a thin layer of material with suitable properties on the polymer surface by plasma techniques, such as sputtering or plasma polymerization or evaporation induced by heating or electron bombardment. Indispensable are different techniques for modification of polymer surface by corona or plasma discharge, irradiation with UV, X, or gamma rays or by electron or ion beams. Interaction of ionizing radiation with polymer molecules leads to creation of free radicals, ions, molecules, or molecular fragments in excited states on the polymer surface. Presence of these reactive species may facilitate subsequent grafting of polymer surface with other bioactive agents.

2.1. Plasma Treatment. Plasma is highly ionized gas consisting of neutral and charged particles including ions, radicals, excited molecules, and "free" electrons [13]. The energy of these particles and the depth of their impact are an important physical parameter for polymer surface modification [14]. By plasma treatment the polymer surface chemistry can be modified to the depth of "few" tens or hundreds of nanometres [15], but the polymer bulk properties remain unchanged. Interaction with plasma leads to creation of free radicals, ions, molecules, or molecular fragments in excited states on the polymer surface. These active species recombine by different processes (e.g., electron-positive ion, positive ion-negative ion, or radical-radical interactions), and new, more stable structures are formed on the polymer surface [16]. In case of reactive plasma modification the electrical field causes acceleration of free electrons; electron kinetic energy becomes sufficiently high to cause ionization, fragmentation, and excitation processes of gas molecules. Thus the activated atoms and molecules generate highly reactive gas mixture, which is able to react chemically with exposed surface [16]. In a macroscopic scale, the plasma treatment may result in surface cleaning or surface ablation or etching of polymer substrate [15].

The plasma sources can be divided into gas, vacuum arc, and laser types. In case of gas sources the plasma ignition is started by application of high voltage to electrodes, while the working gas is blowing in the space between them. Depending on the gas used ( $\mathrm{Ar}, \mathrm{He}, \mathrm{Ne}, \mathrm{N}_{2}, \mathrm{H}_{2} \mathrm{O}, \mathrm{CO}_{2}$, $\mathrm{SO}_{2}, \mathrm{NH}_{3}$, halogens, and their mixtures), the various types of functional groups are created on the polymer surface and the surface properties may be improved according to requirements of different applications [17]. The polymer surface chemistry, morphology, and biocompatibility [1822] have been found to depend strongly on the type of plasma, plasma exposure time, and discharge power. Further modification of plasma-treated polymers may be accomplished by grafting of suitable molecules via covalent bonds to the polymer macromolecules [23]. Grafting with amino acids, peptides, anticoagulant, or antiplatelet agents has been reported $[24,25]$. To improve compatibility with cells, polymer surfaces have also been coated with a thin protein layer (e.g., collagen or fibronectin) $[26,27]$.

\subsection{Excimer Treatment}

2.2.1. Excimer Lamp. It was demonstrated that the attractiveness of uncoated polytetrafluoroethylene (PTFE) for colonization with living cells in vitro can be markedly improved by exposure of the polymer to UV light with wavelengths $200 \mathrm{~nm}$ in a reactive $\mathrm{NH}_{3}$ atmosphere [2831]. UV processing is especially suitable for micropatterning due to the availability of easy-to-use and well-established techniques such as direct writing or mask projection [32]. The photochemical modification technique of PTFE can be suited for spatial control of cell attachment at a typical lateral scale used for cell arrays and also for gene-transfected cells [33]. The adhesion, proliferation, and viability of human umbilical vein endothelial cells (HUVECs) and human embryonic (HEK) kidney cells on excimer lamp-modified spots at PTFE surfaces was studied in [33]. The viability of the cells was assessed using an aqueous nonradioactive cell proliferation assay. Round spots with a diameter of $100 \mathrm{~mm}$ were modified by exposure to the ultraviolet (UV) light of a $\mathrm{Xe}_{2}{ }^{*}$ excimer lamp at a wavelength of $172 \mathrm{~nm}$ in an ammonia atmosphere employing a contact mask. The adhered cells on the spots proliferated. This resulted in a significant increase in the number of adhering HUVECs or HEK cells after seeding and in the formation of confluent cell clusters after 3-4 days [2]. With higher-start seeding density, these clusters were not only confined to the modified spots but extended several micrometer to the neighbourhood. The high potential of the cell microarrays for gene analysis in living cells was demonstrated with HEK cells transferred by yellow fluorescent protein (YFP).

It is hardly possible to place selectively individual cells of different origin or cell type [33], for example, on a defined spot. To obtain this, also the cell adhesion has to be confined to the area of the spots only, at least to their near surrounding. One approach is to coat the whole biocompatible surface with a polymer nonadhesive for cells (e.g., polyethylene glycol (PEG) or a fluoropolymer) and to remove in a second step the polymer layer on the spots, preferentially, by laser ablation [34]. The disadvantage of this method is the possible contamination by debris products of the laser processing. An alternative method without material removal is to modify a nonbioactive surface in such a way that the spot areas become selectively adhesive for cells. This can be achieved, for example, by plasma treatment using shadow masks [35]. In order to obtain cell-interactive, biocompatible surfaces, radiation treatment in general has been extensively investigated. Frequently, these techniques include exposure of various polymeric materials to plasmas, ion beams, electrons, gamma rays, and UV photons [36].

2.2.2. Excimer Laser. It was shown that the illumination of polymers by polarized UV laser beam can induce formation of self-organized ripple structure, the formation being observed within a narrow laser fluence range well below the ablation threshold $[6,37,38]$. The period of the ripples depends on the laser wavelength and the angle of incidence of the radiation (see Figure 1). Their direction is related to the laser beam polarization [27]. The behaviour of 


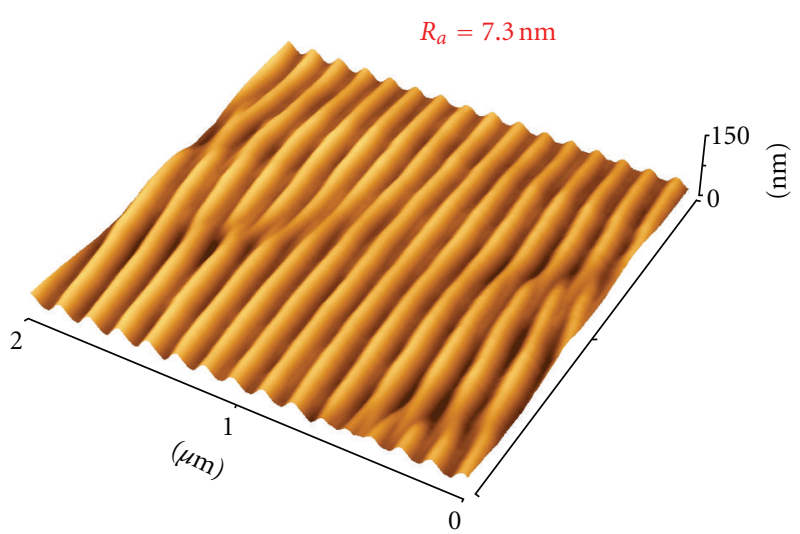

(a)

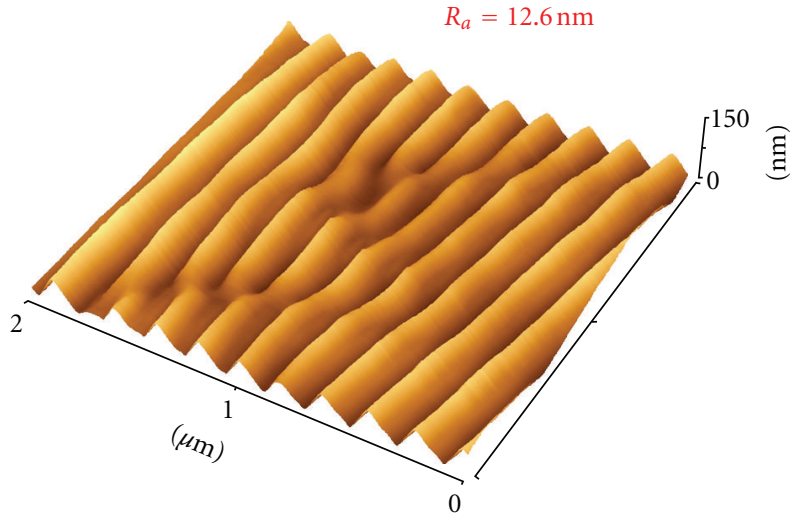

(b)

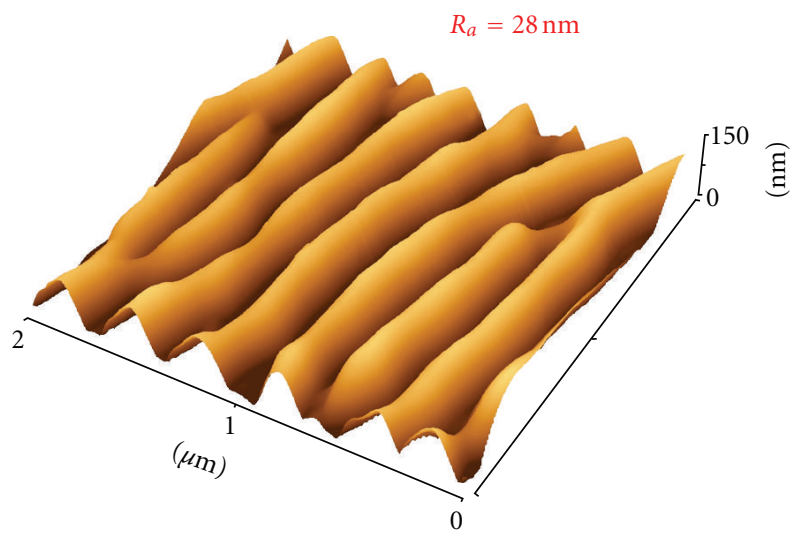

(c)

Figure 1: AFM images of PET samples irradiated with $157 \mathrm{~nm}$ laser $\left(4.40 \mathrm{~mJ} / \mathrm{cm}^{2}\right)$ under different angles of laser beam incidence; (a) angle of incidence $0^{\circ}$ (perpendicular to the sample surface), (b) $22.5^{\circ}$, and (c) $45^{\circ} . R_{a}$ is average surface roughness in nm [6].

human embryonic kidney (HEK-293) cells, Chinese hamster ovary (CHOK1) cells, and skeletal myoblasts seeded on the polystyrene (PS) foils was investigated [1]. The adhesion and proliferation of cells on the irradiated PS foils were enhanced in comparison to those on the pristine PS [1]. Furthermore, the alignment of the cells is along the direction of the ripples. The degree of the cell alignment is celltype dependent and occurs only when the periodicity of the nanostructures is above a critical value [1]. It appears that the biocompatibility depends significantly on the surface roughness. It is known that the optimal microroughness is strongly cell-type dependent [39], and for many cell types, an additional nanoroughness promotes cell adhesion and proliferation $[40,41]$. For mammalian cells, an adhesion to the polymer surface of an implant or a cell culture substratum plays an essential role for many processes, such as cell growth, proliferation, and differentiation [42].

Cells attach to the surface via focal adhesion points, connecting the surface to the cytoskeleton. Formation of these interfaces is not only affected by the surface chemistry (including the presence of ligands), electrostatic charge, wettability (surface polarity), and elastic modulus of the polymeric substrate [21]. Surfaces can also provide microand nanosized topographical clues to guide the alignment, migration of cells or outgrowth along a specific orientation [43]. Mechanical embossing of polyester films provides a convenient method to fabricate a grooved surface to study contact guidance of murine cells. The cells align primarily during attachment and spreading, regardless whether they were seeded onto the surface after trypsination or whether they originated from mitosis of cells detaching from surface during culture. While both cell lines displayed orientation angles deviating little from the direction of the grooves, differences became apparent when analyzing the dynamics of cell attachment and spreading [33]. A cell follows bipolar dilation with little lateral expansion (apart from a prototypical CHO cell, melanocytes would be a good example). It may be feasible to describe the response to various surface geometries in a dose-response fashion as successfully done by several authors [44].

2.3. Grafting and Thin-Layer Deposition. As the supplemental biodegradable structures for tissue engineering materials of different properties, mostly three types-ceramics and natural or synthetic polymers [45] — grafted with biological active species are being studied. Using of composites, for example, matrix composed of different phases, has become more common in the last decade. Polymers as biomaterials 
are represented, for example, by synthetic polylactides, polyglycosides, polycaprolactones and their copolymers, or those from the family of natural polymers for example, collagens, proteoglycans, and substrates on alginate and chitosan base $[45,46]$. Cell affinity of biomaterials involves two main aspects, which are cell adhesion and consequently cell growth. The anchorage of cells in the first stage of cellmaterial interaction is being the most important for the ability of consequent cell proliferation and differentiation in the contact with an implant. Cell adhesion is of great importance influencing the cell growth, migration, and differentiation of cell functions [47, 48]. The adhesion of cells on the growth substrate is mediated in two ways: nonreceptor- or receptor-mediated ones. The nonreceptor one is mediated by nonspecific cell-substrate interaction with the so-called weak chemical bonds (e.g., van der Waals's or hydrogen bond, electrostatic, polar, or ion interaction) of different types of molecules in cell membrane and functional groups of biocompatible substrate. The receptormediated one is cell adhesion with acting of molecules from extracellular matrix. These molecules could be, for example, fibronectin, vitronectin, or collagen. These molecules can be adsorbed on material surface from the matrix in vitro or from body liquids in vivo. Adhered cells are bonded on specific amino acidic sequences of these molecules by means of integrin receptors placed in cytoplasmatic membrane [49]. Integrines are heterodimers consisting of one alpha and one beta subunits, which can be combined and create receptors for specific sequences of amino acids [50]. For adhesion it is essential the presence of sequence containing at least three amino acids on the extracellular matrix molecules, which is very often represented by the sequence Arg-Gly-Asp (RGD sequence) $[49,50]$.

2.3.1. Nanoparticle Grafting. Nanotechnology is undergoing rapid development, and it is expected to produce innovations in different fields. It plays a crucial role in various biomedical applications, not only in targeted drug delivery but also in molecular imaging, biomarkers, and biosensors [51-56]. Nanoparticles can be prepared either from organic materials (e.g., polymers) or from inorganic ones (e.g., metal nanoparticles). Metal nanoparticles, with their specific properties, are being intensively studied both in fundamental sciences and for their potential usage in a broad range of technological and biological applications as well. The dimension of nanoparticles is below the micrometer range (which is cell dimension); their typical size varies in interval from several nanometres to hundred of nanometres (clusters of atoms). The interaction of cells with polymer nanoparticles was reviewed in [51]. The interaction of biodegradable (PLLA, PCL, PLGA) and non-biodegradable (PMMA) nanoparticles with cells is described in detail. Some specific physical or chemical effects, for example, optical properties of nanoparticles (gold nanoparticles, exhibit different colours depending on their dimension, fluorescent "quantum dots"); supermagnetism of small magnetic nanoparticles can only be observed on nanometer-sized particles [57]. In cell biology one of the effects that seems to be specific for materials in the size range of $50-200 \mathrm{~nm}$ is the uptake of nanoparticles by a wide variety of cells $[58,59]$.

An important task of tissue engineering is proliferate cell obtained from the body and at the same time to maintain their activity. It was found that unique surface properties of nanophased materials could not only influence adhesion of surface area and interconnectivity in the constructs but also provides structural and organizational stability for cells [60]. Many naturally derived or synthetic materials were synthesized for use as temporary structures providing a template that allows the body's own cells to grow and form new tissues while the scaffold is gradually absorbed, such as chitosan [61, 62], polyglycolic acid (PLA) [63], or polylactic acid (PGA) [64].

Especially in last few years the interaction of nanoparticles with living cells has been intensively studied. The investigation of this phenomenon brings a lot of promises in the area of cellular therapy and offers great opportunities for tissue engineering or organ replacements. Targetednanoparticle drug delivery is one of the most promising techniques for increasing the efficiency of drugs [65] and also of influencing the differentiation of stem cells. The specific molecules can be prepared as "smart darts," and the nanoparticles are then used as a specific carrier, which enables delivery of "smart drugs" directly to the place where needed.

Noble metal nanostructures attract much interest because of their unique properties, including large optical field enhancements resulting in the strong scattering and absorption of light. The ability to integrate metal nanoparticles into biological systems has greatest impact in biology and biomedicine [66]. Noble metals are used in biomedicine because of their ability to resist corrosion at physiological conditions and their advantageous mechanical properties, their chemical inertness, and relative mechanical softness, for example, silver has long known antimicrobial properties and gold has shown the low allergenic response. Shukla at al. suggested [67] that Au nanoparticles are not cytotoxic, reduce the production of reactive oxygen and nitrite species, and do not elicit secretion of proinflammatory cytokines TNF- $\alpha$ and IL1- $\beta$, making them suitable candidates for nanomedicine. Their studies thus underline the noncytotoxic, nonimmunogenic, and biocompatible properties of gold nanoparticles with the potential for application in nanoimmunology, nanomedicine, and nanobiotechnology [67]. Although important for the final outcome of biomaterials, little is reported about early events between pure noble metals and blood [68]. There are a lot of approaches on how to stabilize gold nanoparticles (AuNPs). Thiolstabilized AuNPs can exhibit desired reactivities due to the variety of functionalizations and the strong $\mathrm{Au}-\mathrm{S}$ bond between the soft acid $\mathrm{Au}$ and the soft thiolate base [69]. The formation of self-assembled mono- and multilayer films of small-ligand-stabilized metal nanoparticles opens to applications as separative layers and chemical sensors $[70,71]$. Gold nanoparticles have been proved to influence surface morphology, wettability, and biocompatibility of polyethylene [7] (see Figures 2 and 3). 


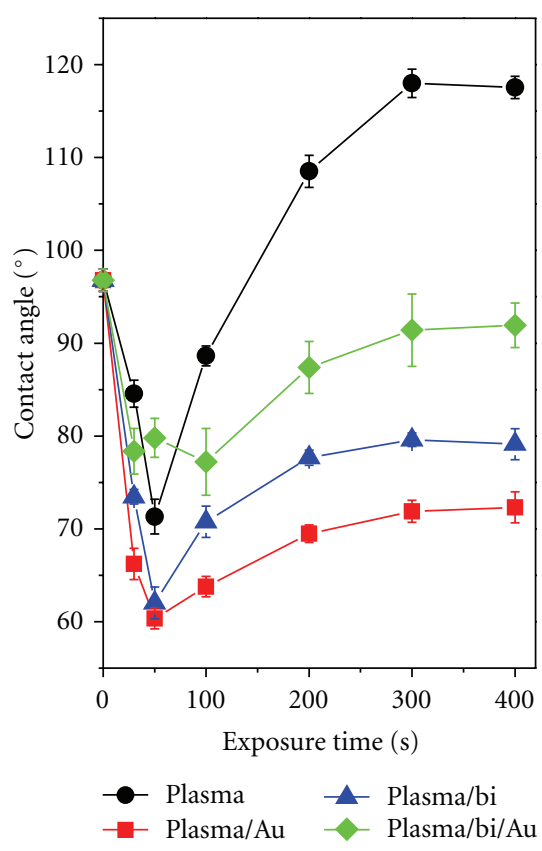

Figure 2: Dependence of the contact angle on the plasma exposure time for pristine $\mathrm{PE}$, plasma-treated $\mathrm{PE}$ (PE/plasma), plasma-treated and $\mathrm{Au}$ nanoparticle-grafted $\mathrm{PE}(\mathrm{PE} / \mathrm{plasma} / \mathrm{Au})$, plasma-treated and biphenyldithiol-grafted $\mathrm{PE}(\mathrm{PE} / \mathrm{plasma} / \mathrm{bi})$, and plasma-treated and biphenyldithiol- and Au nanoparticle-grafted $\mathrm{PE}$ (PE/plasma/bi/Au). The measurement was accomplished 20 days after the plasma modification [7].

Latest new applications of gold nanoparticles may show up in the near future by utilization of nanoparticles in drug release and sensor systems $[67,72]$. Gold is generally considered as inert metal and is more common in, for example, biosensors, because of its electrical conductivity and low solubility. Salts of $\mathrm{Au}$ are known to be of immunological and cytotoxic relevance. Gold nanoparticles with different sizes and shapes have great therapeutic potential as a result of their small size, robust nature, excellent biocompatibility, and unique optical properties, including the wellcharacterized surface plasmon resonance phenomena [73, 74]. It has been found that gold nanoparticles can inhibit the angiogenesis and growth of tumor cells [75]. In addition, gold nanoparticles of various sizes and shapes (nanospheres, nanorods, nanoshells, and nanocages) are used for targeted drug delivery to tumour cells [76] and for photothermal cleavage of cancer [77].

Another example of $\mathrm{Au}$ nanoparticles use is the Bactiguard coating, which is layer comprised of nanosized deposits of Ag, Pd, and Au. The coating can be applied to a large variety of substrates including glass, metal, and polymer surfaces without compromising biocompatibility [78]. Dechent has studied the cytotoxicity of gold nanoparticles [79]. He proved that the cellular response is size dependent, in that $1.4 \mathrm{~nm}$ particles cause predominantly rapid cell death by necrosis within $12 \mathrm{~h}$ while closely related particles $1.2 \mathrm{~nm}$ in diameter effect predominantly programmed cell death by apoptosis. In contrast, gold particles $15 \mathrm{~nm}$ in size or higher are nontoxic at up to 60-fold and 100-fold higher concentrations in comparison with smaller ones [79]. Keratinocytes were immobilized on the gold colloid/chitosan film scaffold and the other two extracellular matrices (ECMs): chitosan film and cell culture plastic (control groups). Many spherical protuberant spots spreading all over the film and roughness of surface relief could be observed, which indicates that the three-dimensional structure was formed. And in comparison to control groups, this scaffold could significantly increase the attached ratio of keratinocytes, which was a determinant event for the subsequent cell proliferation and function [80]. Meanwhile, there were not any fibroblasts growing on this scaffold. The cultured keratinocytes were indentified and characterized by immunohistochemistry and transmission electron microscope (TEM), which showed that the cells conserve their biological activity well. The results indicated that AuNPs/chitosan scaffold was nontoxic to keratinocytes, and was a good candidate for wound dressing in skin tissue engineering.

2.3.2. Carbon Deposition. Different procedures have been used to prepare carbon-polymer composites for medical implant application. Improved biocompatibility of polymer surface doped, for example, with carbon black [81] or carbon fibres [82], was studied. It has also been found that the cell adhesion and proliferation could be affected by carbonization of polymer surface layer by pyrolysis [83], ion implantation [84], UV-light irradiation [29], or exposure to plasma discharge [85]. Both, the biocompatibility of a polymer and its suitable mechanical, electrical, or other properties, are very important for the use as medical implant. The biocompatibility is mainly controlled by the surface properties, whereas the other functional properties are largely determined by the polymer bulk [86]. Another possibility to prepare a polymer-carbon structure is the deposition of carbon layers onto the sample surface. Different carbon forms have been identified in such layers, namely, (i) diamond-like carbon (DLC), (ii) amorphous hydrogenated carbon (a-C:H), amorphous carbon (a-C), (iv) pyrolytic graphite, and $(\mathrm{v})$ fullerene $\left(\mathrm{C}_{60}\right)$ [83, 87]. Methods useful for the preparation of such carbon layers include chemical and physical vapour deposition. Polycarbonate samples coated with DLC films produced by radio frequency glow discharge plasma decomposition are reported to improve blood biocompatibility [88]. Also a-C: $\mathrm{H}$ films produced by plasma immersion ion implantation are claimed to have a positive effect on blood biocompatibility and to abate platelet activation [89]. Another method reported for preparation of a-C: $\mathrm{H}$ layers is magnetron sputtering [90]. Here the adhesion and proliferation of the bone marrow cells were tested with the different amount of $\mathrm{Ti}$ in the carbon films. Amorphous carbon films deposited on metals have been studied as possible structures for biomedical applications mainly because of their chemical inertness and the presence of this element in the human body [91].

The preparation of the carbon layers on PTFE by photoinduced CVD from acetylene, and their physical properties and chemical structure were studied in [8]. These properties 


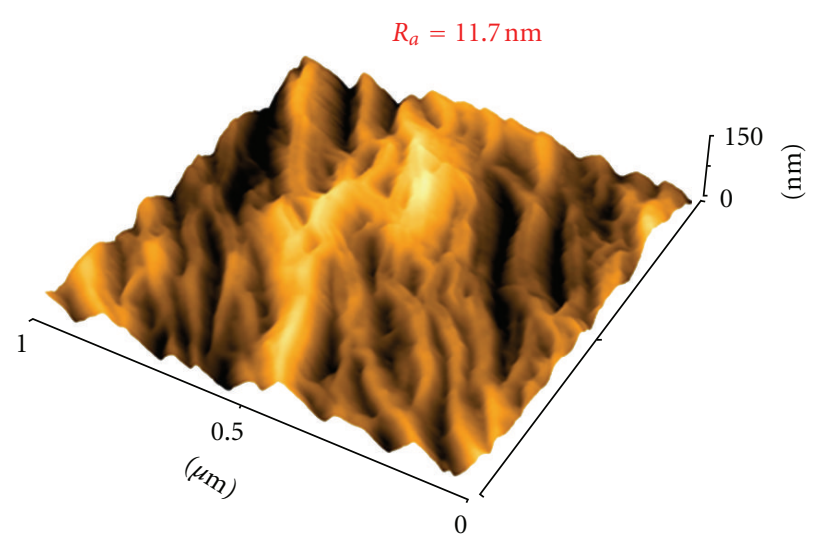

(a)

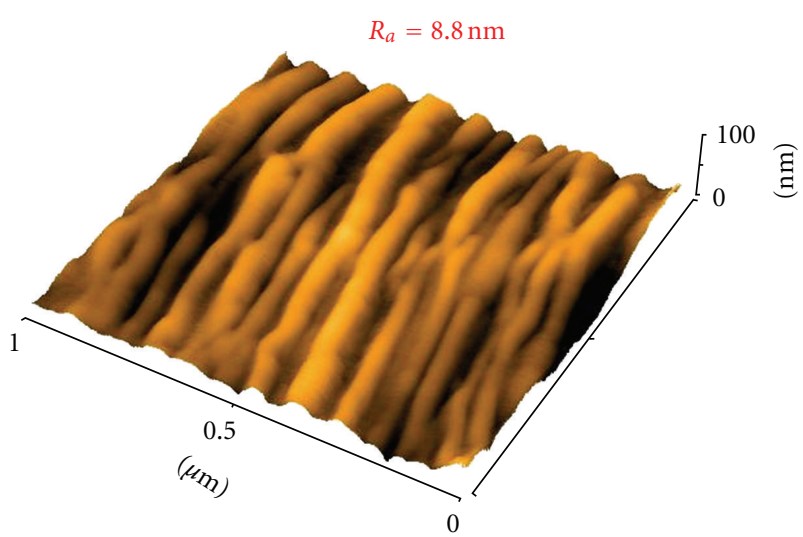

(b)

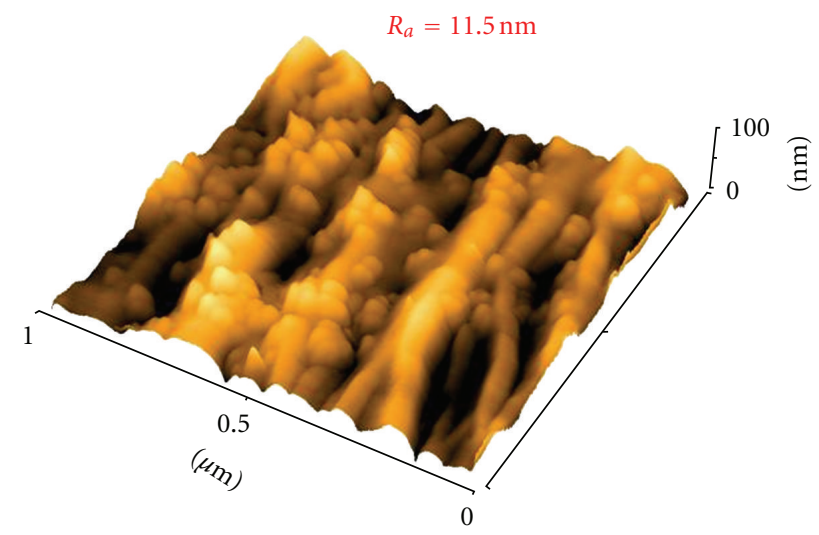

(c)

FIGURE 3: AFM images of the PE treated with plasma for 100 seconds (a), PE treated with plasma and grafted with biphenyl dithiol (b), and PE treated with plasma and grafted with biphenyldithiol and Au nanoparticles (c). $R_{a}$ is the measured surface roughness in nm [7].

were related to the adhesion and proliferation of human umbilical endothelial cells (HUVEC) seeded thereon [8] (see Figure 4). The layers consisted of $\mathrm{C}, \mathrm{H}$, and $\mathrm{O}$ with concentration ratio $\mathrm{C} / \mathrm{O} / \mathrm{H} \approx 45 / 10 / 45$. The initial $\mathrm{C} / \mathrm{H}$ ratio of the acetylene was nearly maintained in the deposited layers. Unsaturated $\mathrm{C}$ radicals in the layer reacted with oxygen. The layers, characterized as a hydrogenated amorphous carbon $(\mathrm{a}-\mathrm{C}: \mathrm{H})$ with an admixture of the oxidized structures, were used for experiments on biocompatibility [8]. In contrast to pristine PTFE, coated PTFE showed very good cytocompatibility, which was demonstrated on endothelial cells (HUVECs) growth. The cytocompatibility was comparable to those of tissue cultured PS, which is the standard substrate in cell cultivation [8].

2.3.3. Grafting of Bioactive Molecules. It is well known that chemical structure and surface morphology have a significant effect on surface wettability (surface polarity) and zeta potential (see Figure 5) [9, 10, 92, 93], which in turn may affect adhesion and proliferation of living cells (Figure 6) [10]. The contact angle, as a measure of surface wettability, has been studied by many authors. It has been found that the plasma treatment results in rapid decrease of the contact angle which can further be affected by grafting with bioactive molecules. The contact angle decrease for plasma-treated PE is mostly related to the formation of oxygen structures during the plasma treatment [94]. Obviously, the oxygen from the ambient residual atmosphere interacts with the plasmaactivated PE surface and creates various oxidized structures. Creation of carbonyl, carboxyl, and ester groups on plasmatreated PE was proven earlier in similar experiments [85]. A further decrease in the contact angle was observed after glycine and PEG grafting, where the hydrophilicity of the sample increased in comparison to $\mathrm{PE}$ treated only with plasma [92]. This finding supports the idea that the polar molecules (Gly, PEG) are linked to the activated PE chain [92]. By contrast, after BSA, C, and BSA + C grafting, the values of the contact angle were higher than that after mere plasma treatment, but lower than that in the case of pristine PE. Covalent grafting of the mentioned (BSA $+\mathrm{C})$ molecules to the polymer surface was proved by the decrease in the concentration of radicals and double bonds on the modified polymer surface [25]. The lack of suitable donor sites of autologous tissue for permanent coverage of wounded bed is solved by production of functional tissue substitutes combining appropriate cell types with suitable artificial substrates, which can be represented by synthetic polymers. Cultured epidermal grafts, attached to polymer 

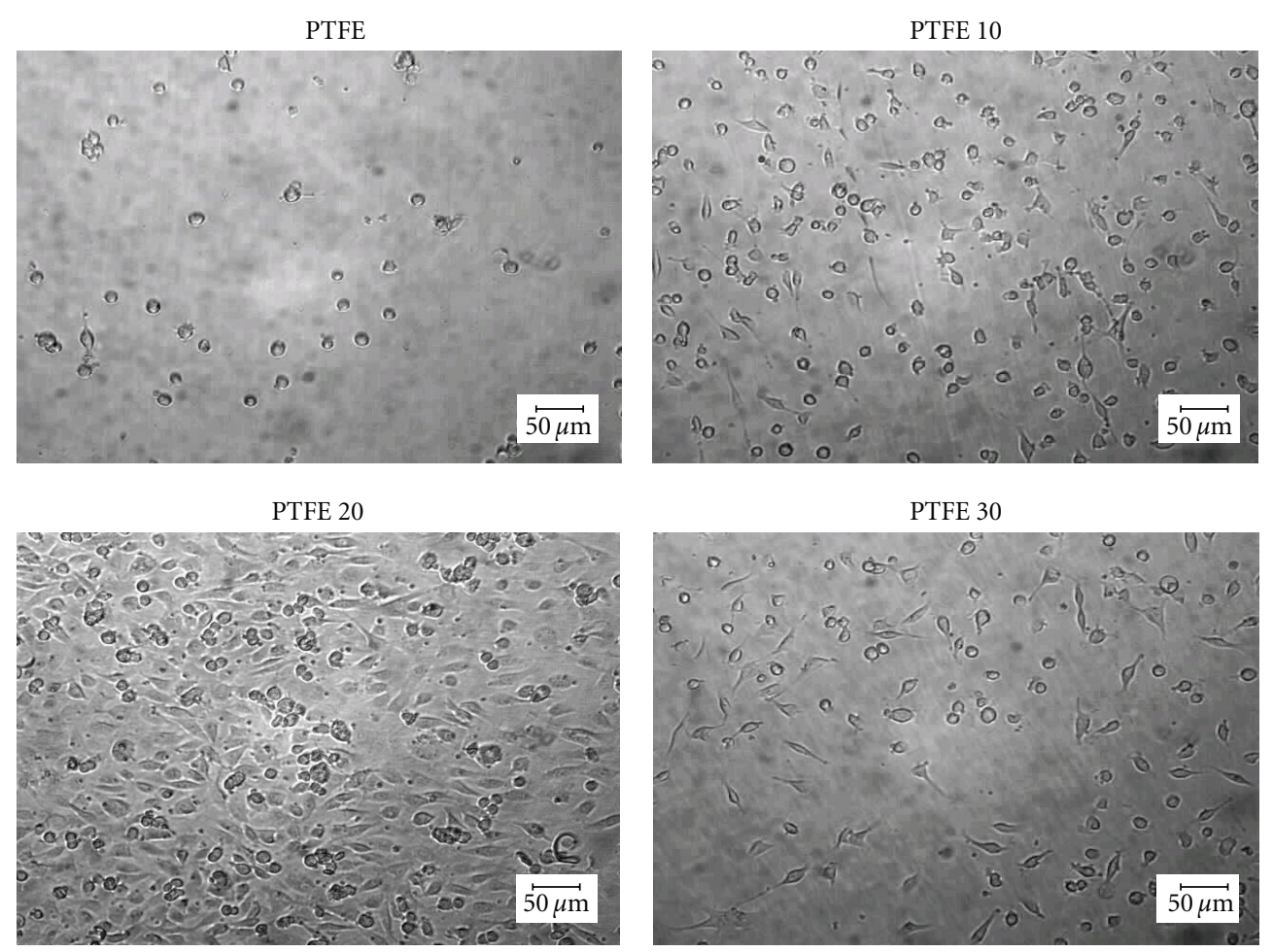

FigURE 4: Phase contrast micrographs of HUVEC (7 days after cell seeding) on pristine PTFE (PTFE) and on PTFE with a carbon layer deposited for 10, 20, and $30 \mathrm{~min}$ (PTFE/C10 to PTFE/C30) [8].

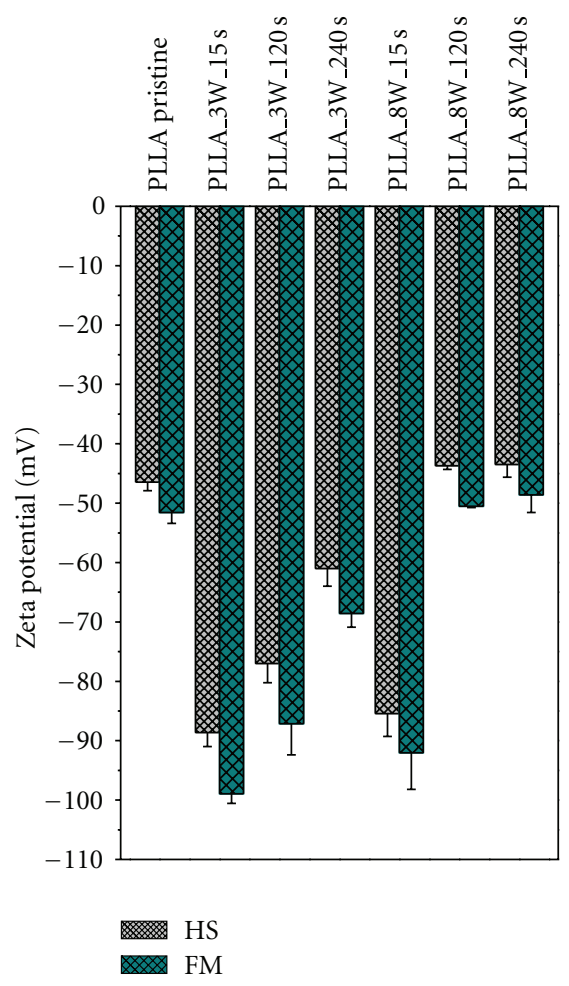

(a)

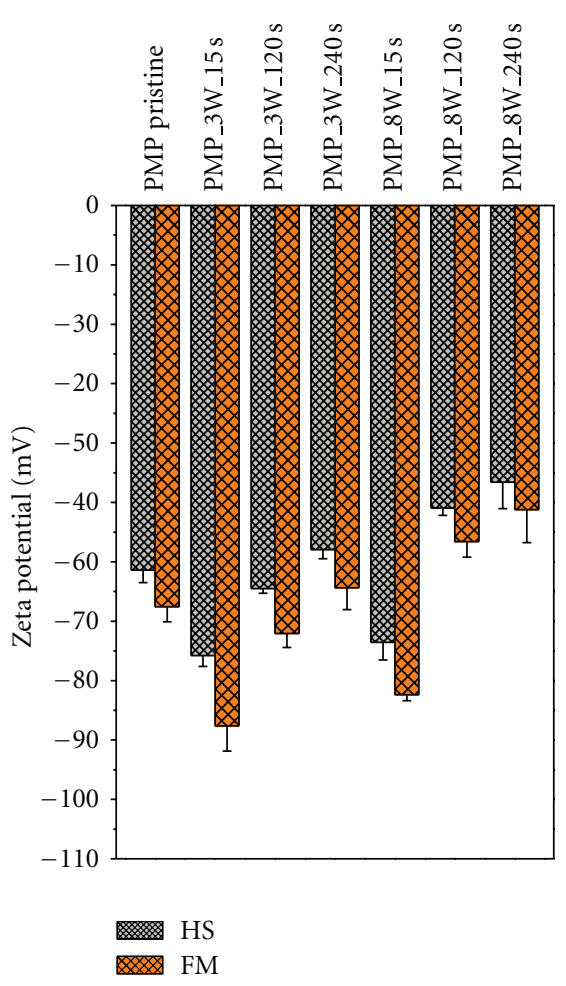

(b)

Figure 5: Zeta potential values of pristine PLLA (a) and PMP (b) and aged samples modified by Ar plasma (power 3 and 8 W) with exposure times 15, 120, and $240 \mathrm{~s}$. The value of zeta potential was determined using streaming current and streaming potential approaches and two equations (Helmholtz-Smoluchowski (HS) and Fairbrother-Mastins (FM)) [9]. 

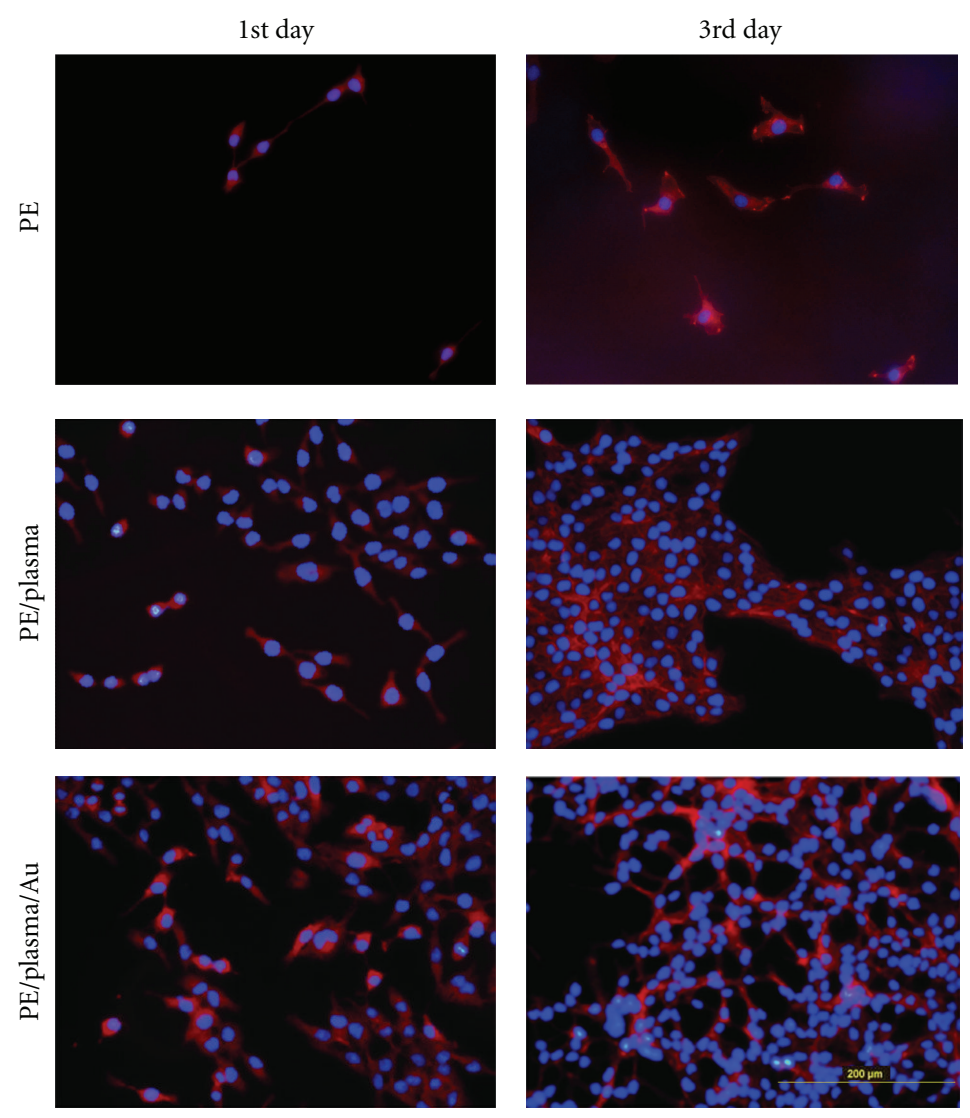

FIGURE 6: The photographs of 3T3 cells adhered (1st day) and grown (3rd day) on pristine PE (PE), PE treated for $150 \mathrm{~s}$ with plasma (PE/plasma), and subsequently grafted with Au nanoparticles (PE/plasma/Au) [10].

carrier, can be transferred to wound bed [95]. The strength of cell adhesion, cell morphology, proliferation activity, and differentiation depends on the physical and chemical surface properties of the polymeric carrier which can be affected by preparatory polymer treatment.

Two basic mechanisms of the cell adhesion on artificial materials are known, direct one without receptor intervention and one with receptor-mediated binding through extracellular matrix molecules or their parts. The molecules can be adsorbed on the material surface from the surrounding environment, that is, cell culture media in vitro or body fluids in vivo. The anchorage-dependent cells bind specific amino acid sequences of these molecules through integrin receptors. The minimum adhesion on ECM molecules should contain at least three amino acids, which are most often represented by arginine-glycine-aspartic acid (RGD). In addition, these ligands for integrin receptors cooperate with synergistic amino acid sequences, which help to maintain the appropriate spatial conformation of these ligands as well as integrin receptors and thus facilitate the integrin-ligand binding $[96,97]$. Functional groups can be grafted onto a polymer by chemical reaction of doted compounds at the site of polymer chain defect (free radical, double bond) [97]. In this way grafting of carboxylic acid [97] or amino acid [98] was realized on polymer, the biocompatibility of which was studied by in vivo technique. It was found that the amino acid grafting facilitates adhesion and proliferation of cells on the surface of modified polymers. The compositional and structural changes of polyethylene, induced by the irradiation with $15 \mathrm{keV} \mathrm{Ar}{ }^{+}$and $\mathrm{Kr}^{+}$ions and subsequent grafting with peptide RGD sequence, were studied in [92].

\section{Selected Substrates for Biocompatibility Enhancement}

Synthetic polymers, such as polyethylene (PE), polystyrene (PS), polyurethane (PU), polytetrafluoroethylene (PTFE) and polyethylene terephthalate (PET) $[1,2,4,7,12,17$, $24,25,28,29,81]$ are commonly used in various fields including biotechnology, medicine, and tissue engineering studies. These materials not only serve as growth supports for cell cultures in vitro but can also be used for constructing replacements for various tissues or organs, for example, nonresorbable or semiresorbable vascular prostheses, artificial heart valves, bone and joint replacements, and implants for plastic surgery [17]. Materials designed for the construction of body implants must be biocompatible, that is, matching the mechanical properties of the replaced tissue and not acting as cytotoxic, mutagenic, or immunogenic. On the other hand some of biocompatible materials can also behave as bioinert, that is, not promoting cell adhesion and proliferation. For example, these types of material have 
been already applied in the construction of artificial eye lenses and in articular surfaces of joint prostheses, that is, implants requiring transparency or smoothness, and thus completely cell-free surfaces. Bioinert materials have also been used for fabricating polymeric vascular prostheses in order to prevent adhesion and activation of thrombocytes and immunocompetent cells on the inner surface of these grafts [49].

It has been described in many investigations that watersoluble porphyrins and related macrocycles are able to form supramolecular complexes and ordered structures on the surface of inorganic substrates [99] as well as on polar or oppositely charged molecular scaffolds, polypeptides [100], proteins [101] nucleic acids [102], polysaccharides [103], cyclodextrins [104], dendrimers, synthetic polymers [105], surfactants, or mitochondrial membranes [106]. Being achiral molecules, these macrocycles can demonstrate induced chirality in their complexes and aggregates obtained by interaction with chiral environment. Therefore, scaffold biological macromolecules promote self-forming of chiralordered porphyrin arrays. Chitosan, a natural polysaccharide, has been found to be a useful biomaterial [107]. Due to the presence of amino groups in the molecule, chitosan is soluble in aqueous acidic media. It forms viscous solutions that can be applied to produce gels, membranes, beads, coatings, fibres, and sponges. Chitosan is a biocompatible, biodegradable, biologically inert, and stable material. These properties make it suitable for use in a number of biomedical applications, including artificial skin, tissue regeneration, and drug delivery systems.

Fullerenes, that is, spherical molecules, made exclusively of carbon atoms (e.g., $\mathrm{C}_{60}, \mathrm{C}_{70}$ ), display a diverse range of biological activity [108]. Their unique hollow cage-like shape and structural analogy with clathrin-coated vesicles in cells support the idea of the potential use of fullerenes as drug or gene delivery agents [109]. Fullerenes are able to accept and release electrons. When irradiated with ultraviolet or visible light, fullerenes can convert molecular oxygen into highly reactive singlet oxygen. Thus, they have the potential to inflict photodynamic damage on biological systems, including damage to cellular membranes, inhibition of various enzymes or DNA cleavage [110]. This harmful effect can be exploited for photodynamic therapy against tumours, viruses and bacteria resistant to multiple drugs [111]. On the other hand, $\mathrm{C}_{60}$ is considered to be the world's most efficient radical scavenger. This is due to the relatively large number of conjugated double bonds in the fullerene molecule, which can be attacked by radical species. Thus, fullerenes would be suitable for applications in quenching oxygen radicals and thus preventing the damage of various tissues and organs, including the cardiovascular and central nervous systems [112]. In addition, fullerenes emit photoluminescence which could be utilized in advanced imaging technologies [113]. In their pristine unmodified state, fullerenes are highly hydrophobic and water insoluble. On the other hand, they are relatively highly reactive, which enables them to be structurally modified. Fullerenes can form complexes with other atoms and molecules, for example, metals, nucleic acids, proteins, and synthetic polymers as well as other carbon nanoparticles (e.g., nanotubes). In addition, fullerenes can be functionalized with various chemical groups, for example, hydroxyl, aldehydic, carbonyl, carboxyl, ester, or amine group, as well as amino acids and peptides. This usually renders them soluble in water and intensifies their interaction with biological systems. It is believed that nanostructured surfaces can promote preferential adhesion and growth of osteoblasts over other "competitive" cell types, including fibroblasts, and thus they can prevent fibrous encapsulation and loosening of bone implants. It is considered that the underlying mechanism is higher adsorption to the nanostructured surfaces of vitronectin, an extracellular matrix (ECM) protein preferred by osteoblasts [114]. Therefore, it can be expected that carbon nanoparticles, including fullerenes, may serve as novel building blocks for creating artificial bio-inspired nanostructured surfaces for bone tissue engineering [115].

Cellulose is one of the most widespread natural polymers. Due to its ubiquity in nature and longstanding touch with people the cellulose, and its derivatives are generally respected as the safest and the most acceptable polymer group for the utilization in food and pharmaceutical products. Cellulose is a natural material without some chemical contaminants (e.g., residual monomers, initiators, or catalysts), which are usually present in synthetic polymers. 6-Carboxycellulose (thereinafter oxycellulose) is one of cellulose derivatives. Oxycellulose bioresorbability in tissues is given by its high degradation rate. Oxycellulose is biocompatible and biodegradable polymer without unfavourable effects on human body. The possible usage of oxycellulose and its derivatives could be, for example, as biocompatible absorbable materials for wound care, hemostatic dressings, absorbable local hemostatic agents, drug transport systems, or chronic wounds and burns treatment [116]. Oxycellulose is used in surgery due to its suitability in all wound healing stages. It stops bleeding when acts as a matrix for the clot formation. Neutralized forms of oxycellulose, especially sodium, magnesium, and calcium salts, are very well tolerated by organisms. Due to the neutral $\mathrm{pH}$ of water leach, the neutralized oxycellulose forms do not cause irritation and sensibility of tissue and they are easily absorbed. Calcium, which is one of the inflammation mediators, enters as a cofactor into a blood clotting mechanism and initiates a moving of immune cells to the injured place. This starts a healing process of the wound. By this way the better environment to heal up the wound is created and smoother scars are formed. The clinical practice showed that the application of the calcium salt of 6-carboxycellulose (Ca-oxy) caused a partial easement from the pain even without using local anaesthetics. It is assumed that $\mathrm{Ca}^{2+}$ ions tend to block a neurotic impulse transfer. Interaction between polyethylene film doped with calcium salt of 6 carboxycellulose and 3T3 fibroblasts, which serve as a feeder for keratinocytes adhesion and proliferation, was demonstrated [117]. The possibility of usage as a new substrate for cell cultivation was investigated. Because the previous experiments showed that foil formed only from Ca-oxy decomposes in culture medium, some polymer matrix had to be chosen. $\mathrm{PE}$ is one of the most used polymers in medicine (e.g., artificial 
joints); thus it seemed to be a good candidate for the matrix. The surface of doped PE films was characterized by contact angle measurement and SEM microscopy. The surface morphology was determined by profilometry. The possibility of an enhancement of cytocompatibility of the doped polymer substrate surface by grinding was also studied [117].

\section{Cells Interaction with Nanostructured Surface}

As was discussed above modification of already irradiated or plasma-treated polymers may be accomplished by grafting with suitable molecules, including amino acids, peptides, anticoagulant, or antiplatelet agents, which may be fasten via covalent bonds to the polymer macromolecules [23-25]. For improved compatibility to cells, plasma-modified polymer surfaces are often coated with a thin protein layer (e.g., collagen or fibronectin) [27] or grafted with functional parts of these proteins. In an indirect approach the modification may facilitate the adsorption of cell proteins, present in the serum of the culture media. Some of these proteins are adhesion mediating and contain sequences of amino acids, which bind specifically to the adhesion receptors in the cell membrane, for example, integrins [118]. After ligand binding, the integrins associate with structural and signalling molecules, so that the signal from the surrounding environment can be delivered into the cells. It should be noted that the enhanced biocompatibility of the modified polymer surfaces is due not only to the presence of new chemical groups but also to increased surface polarity and wettability. Also the sign of an electrical charge at the surface is important for cell adhesion.

An alternative and more advanced approach, widely accepted in contemporary tissue engineering, is to create surfaces that support colonization with cells and good integration of a replacement with the surrounding tissues of the patient's organism. This concept is used for example, for constructing bone prostheses that will persist in the patient's organism for many years and is being developed for the creation of bioartificial replacements of blood vessels, liver, pancreas, and even nervous system tissue. In these replacements, the artificial materials have a similar function as the natural extracellular matrix, and they serve as templates for regeneration of the damaged tissue. For example, in vascular tissue engineering, such a material should enable reconstruction of the tunica intima, formed by a confluent layer of endothelial cells, and also reconstruction of the tunica media containing vascular smooth muscle cells. For such purposes, advanced artificial materials cannot merely be passively tolerated by cells but should act as bioactive or biomimetic, that is, inducing the required cell responses in a controllable manner [17, 49].

The cell-material interaction is strongly dependent on the physical and chemical properties of the material surface. The main properties decisive for colonization of a material with cells are surface polarity, wettability, electrical charge, surface roughness, and morphology. No less important is the presence of various chemical functional groups and biomolecules on the surface of these materials $[49,119]$. Unfortunately, many potential materials for the construction of tissue replacements have properties that are not so appropriate for integration with the surrounding tissues, and they need further modification in order to enhance their attractiveness for cell colonization and new tissue formation. The synthetic polymers mentioned in previous chapters are a typical example. In their pristine state, these materials are characterized by relatively high hydrophobicity (i.e., the water drop contact angle on their surface is usually higher than $\left.90^{\circ}[49,119]\right)$.

Modification of PE samples by plasma discharge and subsequent grafting with biomolecules enhanced the colonization of PE with vascular smooth muscle cells (VSMCs) with numerous talin and vinculin-containing focal adhesion plaques [120]. As suggested by the more numerous and thicker filaments containing a contractile protein alphaactin and also by the higher concentration of this protein per mg of protein, the cells on the modified polymers, particularly those grafted with PEG or glycine, also showed a higher level of phenotypic maturation. The beneficial effect of the plasma discharge on PE foils was attributed to the formation of oxygen-containing structures in the PE surface layer, increased material wettability, and changes in the surface morphology [120]. Oxygen was present not only on the very surface of the sample but also in the underlying surface layer about $50 \mathrm{~nm}$ in thickness. However, water treating of plasma-irradiated PE led to a decrease in oxygen concentration in the surface layer, due to dissolution of plasma-degraded macromolecules in water. On the other hand, ablation of the surface layer by plasma treatment resulted in changes in the polymer surface morphology. Increase in the surface roughness may promote cell adhesion and growth too. Subsequent grafting with biomolecules (Gly, PEG, BSA) and colloidal $C$ particles further increased the attractiveness of plasma-modified PE for VSMC colonization [120]. Grafting with glycine and PEG further increases the oxygen concentration on the PE surface and its surface wettability. The supportive effect of biomolecules on cell colonization was most apparent on the polymer modified by PEG and BSA + C molecules.

Adhesion and proliferation of rat VSMCs were studied on pristine PE, PE modified by plasma, and PE modified by plasma discharge and subsequently grafted with PEG (of different molecular weight). Grafting of PE with short PEG chains preserved the PE lamellar structure, but grafting with longer PEG chains produced branched star-like formations on the PE surface [11]. The biological in vitro experiments with VSMCs show that PEG grafting does not increase cell adhesion but it increases dramatically cell proliferation (see Figure 7) [11]. The antiadhesive action of PEG is due to its very high hydrophilicity and mobility of its chains, which hamper stable adsorption of the proteins that mediate cell adhesion. However, at the same time, the antiadhesive action of PEG is strongly dependent on its concentration on the polymer surface and on the length of its molecular chain too. Lowest adhesion was observed on the PE grafted with PEG of molecular weight $M=300 \mathrm{~g} / \mathrm{mol}$. Higher adhesion 


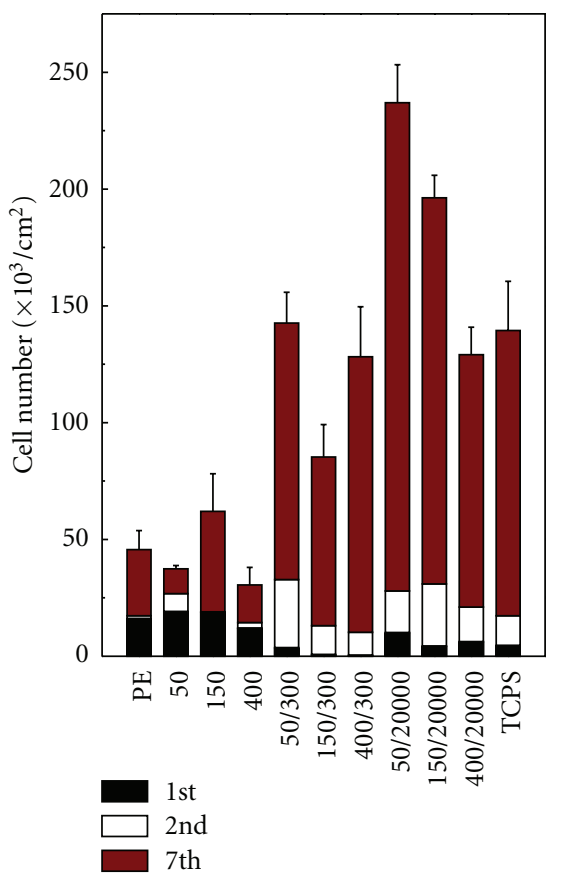

FIgURE 7: Dependence of the number of VSMC cells on the cultivation time for pristine PE (PE), PE plasma modified for 50, 150, and $400 \mathrm{~s}$ (50-400) and subsequently grafted with PEG (molecular weight $M=300 \mathrm{~g} / \mathrm{mol}, 50-400 / 300$ ), and PEG (molecular weight $M$ $=20000 \mathrm{~g} / \mathrm{mol}, 50-400 / 20000)$ and tissue polystyrene (TCPS) [11].

was found on the PE grafted with PEG $(M=20000 \mathrm{~g} / \mathrm{mol})$ and on the TCPS. Much better cell growth was observed on the samples grafted with PEG of higher molecular weight. After 7 days of cultivation, the cells were still well spread, but their distribution was not homogeneous and cell aggregates appeared. On the contrary, on the plasma-modified and PEG-grafted PE, a density and homogeneous cell coverage is observed after 7 days of cultivation, in spite of the fact that the grafting did not affect initial cell adhesion.

Treatment in the plasma discharge leads to cleavage of original macromolecular chains on the PE surface, creation of free radicals, and excessive double bonds. Reaction with oxygen from ambient atmosphere in the reaction chamber or after exposing the samples to the atmosphere results in formation of various oxygen-containing structures which increase surface wettability $[121,122]$ and which may facilitate the cell adhesion $[10,29,123]$. Contact angle decreases dramatically after the plasma treatment and the decrease is inversely proportional to the time of the plasma treatment. Water etching results in a decrease of the oxygen concentration in the polymer surface layer. This decrease indicates dissolution of a part of the oxidized structures or low-molecular-weight fragments [121]. An increase of the oxygen concentration after the PEG grafting shows chemical binding of a part of PEG molecules on the surface of the plasma-modified PE. Surface morphology is well known to affect the interaction of cells with polymers $[123,124]$. Also Guo et al. [125] confirmed that the PEG-modified surfaces did not significantly support the cell adhesion but did promote the differentiation and proliferation of cells. The adhesion, proliferation, and differentiation of the MSCs (human mesenchymal stem cells) could be controlled by surface chemistry. The electrostatic properties of a biomaterial surface could affect cell functions such as cell adhesion, proliferation, and differentiation [125].

HUVECs (human umbilical vein endothelial cells) were seeded on the pristine PTFE and PTFE coated with different carbon layers. The cell adhesion was studied after 1 day, the proliferation after 3 and 7 days of cultivation [8]. The amount of cells was determined by counting from images and MTS test. The adhesion of cells on PS and PTFE with photodeposited carbon was comparable, but clearly higher than that on pristine PTFE. The positive influence of the photodeposited carbon layer for cytocompatibility was proved to be more significant after 3 and even more after 7 days of proliferation. These values were comparable or even higher than the values on tissue PS at the same day. The highest amount of cells was significant on the sample coated for $20 \mathrm{~min}$ by carbon. Here the cells were spread onto the surface and have a polygonal shape [8]. They formed a nearly confluent cell layer on the surface. The large difference in cell adhesion and proliferation between pristine PTFE and carbon-coated PTFE allows to confine the cells to certain areas at the surface. The possibility to confine the spots on certain areas at the surface opens a wide field of possible applications, including the fabrication of cell microarrays for high throughput screening. The photo-induced deposition of carbon stimulated proliferation of cells in comparison with pristine PTFE. From our previous work [2], it was suggested that a "good" wettability seems to be important and has positive influence on the adhesion and proliferation of cells and especially HUVEC [8]. Nanostructures supporting cytocompatibility are reported to have a height of about $10 \mathrm{~nm}$ and a lateral spacing below $75 \mathrm{~nm}$ [40]. As shown in [8], the carbon layers deposited on the PTFE surface have a distinct nanotopology which has been featured in these dimensions. Therefore, the best cytocompatibility of carbon layers photo-deposited for $20 \mathrm{~min}$ may be related to the best suited nanoroughness for the interaction with HUVEC.

The physicochemical properties of polyethylene films doped with calcium salt of 6-carboxycellulose (Ca-oxy) in concentrations $0-20 \mathrm{wt} . \%$ and their interactions with cells were studied in [117]. Modification by surface grinding to enhance material cytocompatibility was performed. The surface wettability of doped films was tested by contact angle measurements and the surface morphology by SEM microscopy and profilometry. Adhesion and proliferation of tissue cells (3T3 mouse fibroblasts) were studied in vitro on pristine and ground-doped PE films. The ground samples had a higher contact angle values, and the number of proliferated cells is greater on the ground samples than that on pristine ones. The presence of Ca-oxy in PE film increased the adhesion of 3T3 cells on the doped substrate and on ground samples adheres that more cells than on pristine ones. An interaction between the calcium salt of 6carboxycellulose (Ca-oxy) in PE film and 3T3 fibroblasts, which serves as a feeder for keratinocytes adhesion and proliferation, was studied [117]. It was found that the water 
contact angle of the doped films decreases with increasing Ca-oxy concentration up to $10 \mathrm{wt} . \%$. The contact angles of $\mathrm{PE}$ with the Ca-oxy concentration above $10 \mathrm{wt} . \%$ increased due to the rising of the surface roughness. The greater the Ca-oxy concentration, the more the 3T3 fibroblasts tend to agglomeration and to smaller spreading area. It was shown that the homogeneity of the adhered cells depends on the surface wettability and topology of the polymer film [117]. The surface morphology of the samples changed significantly with increasing Ca-oxy concentration. The doping of PE increased the 3T3 cells adhesion to the polymer substrate. Using grinding modification it is possible to achieve the significant changes in the morphology of the doped PE, which have a positive influence on the cell adhesion and proliferation. The doped PE modified by grinding could serve as substrate for cell cultivation on materials intended for skin injury treatment.

The PE samples were modified by implantation with $\mathrm{Ar}^{+}$ or $\mathrm{Kr}^{+}$ions to different ion fluencies and the growth of $3 \mathrm{~T} 3$ cells on pristine and modified PE samples as a function of the ion fluence was studied in [92]. The modification with $\mathrm{Ar}^{+}$or $\mathrm{Kr}^{+}$ions leads to an increase in the average number of adhering cells in comparison with pristine PE. For ion fluences above $10^{14} \mathrm{~cm}^{-2}$, the increase is higher for the samples irradiated with $\mathrm{Kr}^{+}$ions. Additional grafting with RGD molecules results in further increase of the number of adhering $3 \mathrm{~T} 3$ cells, the effect being stronger on the samples irradiated with $\mathrm{Kr}^{+}$ions. Obviously, the more pronounced effect of the irradiation with heavier $\mathrm{Kr}^{+}$ions is connected with higher degree of degradation of the PE surface layer which may facilitate cell adhesion [126, 127]. The RGD-grafted samples exhibit higher homogeneity of cell distribution in comparison with implanted-only samples [92]. The cells on modified PE had a larger spreading area, which was well pronounced especially on RGD-grafted surfaces and thus clearly evidenced positive effect of this type of modification on cell adhesion. Another important factor of biocompatibility is the firmness of the cell adhesion on the PE surface which was estimated by the resistance of cells to the detachment by trypsin [17]. The number of cells remaining on the polymer surface after exposure to trypsin for different times was assessed by measuring of optical absorbance using MTT test [92]. Typical results obtained on pristine $\mathrm{PE}$, implanted-only $\mathrm{PE}\left(\mathrm{Kr}^{+}\right.$ions, $\left.1.10^{14} \mathrm{~cm}^{-2}\right)$, and PE implanted and RGD grafted revealed that the initial number of cells was higher on both types of modified polymers, especially those grafted with RGD, in comparison to pristine PE. The kinetics of cell release suggested that the cells on both types of modified samples are more resistant to trypsin detachment.

Švorčík et al. observed [29] studied cell proliferation on UV-excimer lamp modified and grafted polytetrafluoroethylene (PTFE). It was found that the number of adhering cells is higher for the PTFE samples grafted with amino acids, with largest numbers observed on the samples grafted with glycine. There was no significant difference in the cell adhesion between the PTFE samples grafted with alanine and leucin. Maximum number of initially adhering cells was observed on the sample irradiated for $15 \mathrm{~min}$ and grafted with glycine [29]. In that case the adhesion was six times higher in comparison with only irradiated PTFE. The study of population density of SMC $72 \mathrm{~h}$ after seeding, which could be considered as an indirect measure of cell proliferation, revealed that for each irradiation time the maximum proliferation was observed or the samples grafted with glycine. The irradiation with UV light increased 3T3 cell adhesion significantly. The irradiation for $15 \mathrm{~min}$ resulted in six time higher number of adhering cells in comparison with pristine PTFE. No significant difference in the number of initially adhering cells was observed between samples grafted with leucin and alanine [29]. On unmodified PTFE, the cells were distributed on the surface inhomogeneously. On the irradiated surface, the cells are well spread [29]. Irradiation with UV-light and subsequent grafting with amino acids increased adhesion and proliferation of both cell species, with maximum effect being found for PTFE grafted with glycine [29].

Single amino acid molecules cannot ensure the direct and specific cell adhesion to the polymer through integrin receptors on the cell surface, because these receptors can bind only to sequences of at least three amino acids. Nevertheless, as shown in our earlier studies $[25,123,128]$, alanine could have a beneficial effect on cell adhesion, which is explained by optimal modulation of polymer surface wettability by amine groups. Glycine, alanine, and leucin belong to the same group of amino acids, that is, group with aliphatic chain. They contain one $-\mathrm{NH}_{2}$ and $-\mathrm{COOH}$ group per molecule but they differ in the length and branching of carbon chain, as well as the number of methyl groups which could lead to a (i) different relative concentration of $-\mathrm{NH}_{2}$ groups in the polymer surface layer, (ii) different spatial conformation of all three amino acids resulting. This different "background" of $-\mathrm{NH}_{2}$ group could influence differently the adsorption of adhesion-mediating proteins from the serum in the culture media to the polymer (e.g., vitronectin, fibronectin) and then the cell adhesion. The successful grafting of amino acids [29], which are parts of cell adhesion-mediating amino acid sequences, could be a starting point for construction of more sophisticated structures, such as polymers grafted with these sequences for mediating cell adhesion without problematic (e.g., potentially immunogenic) participation of whole extracellular matrix molecules.

\section{Conclusion}

Modification by plasma discharge, by irradiation with photons or particles, and/or by grafting with specific chemical agents promotes adhesion, growth, and long-term viability of cells on polymer surface. The enhanced polymer bioactivity is due to the favourable changes in physico-chemical properties of polymer surface, in its nanostructure, in surface wettability, and in other properties. The synergetic effect of polymer treatment combined with grafting with bioactive molecules or nanoparticles improves the biocompatibility of polymers significantly. The development of novel bioactive surface coatings of polymers holds promise for tissue engineering and medicine. The newly developed, polymerbased composites could be used for inner modification of 
vascular prostheses, surface coating of heart valves, and also for modifying polymeric carriers for dermal fibroblasts and keratinocytes for skin reconstruction. Other potential applications of these materials are in coating the bonecontacting parts of metallic joint replacements and other bone implants, which would lead to increased integration of these devices with the surrounding bone tissue.

\section{Acknowledgments}

This work was supported by the GACR under Project 108/12/G108. The authors would like to thank to Professor V. Hnatowicz for his language corrections and help.

\section{References}

[1] E. Rebollar, I. Frischauf, M. Olbrich et al., "Proliferation of aligned mammalian cells on laser-nanostructured polystyrene," Biomaterials, vol. 29, no. 12, pp. 1796-1806, 2008.

[2] R. Mikulikova, S. Moritz, T. Gumpenberger et al., "Cell microarrays on photochemically modified polytetrafluoroethylene," Biomaterials, vol. 26, no. 27, pp. 5572-5580, 2005.

[3] J. Y. Lim and H. J. Donahue, "Cell sensing and response to micro- and nanostructured surfaces produced by chemical and topographic patterning," Tissue Engineering, vol. 13, no. 8, pp. 1879-1891, 2007.

[4] B. Reisinger, M. Fahrner, I. Frischauf et al., "EUV micropatterning for biocompatibility control of PET," Applied Physics A, vol. 100, no. 2, pp. 511-516, 2010.

[5] T. Peterbauer, S. Yakunin, J. Siegel et al., "Dynamics of spreading and alignment of cells cultured in vitro on a grooved polymer surface," Journal of Nanomaterials, vol. 2011, Article ID 413079, 10 pages, 2011.

[6] P. Slepička, A. Chaloupka, P. Sajdl, J. Heitz, V. Hnatowicz, and V. Švorčík, "Angle dependent laser nanopatterning of poly(ethylene terephthalate) surfaces," Applied Surface Science, vol. 257, no. 14, pp. 6021-6025, 2011.

[7] N. Slepičková Kasálková, P. Slepička, Z. Kolská, P. Sajdl, L. Bačáková, and V. Švorčík, "Cell adhesion and proliferation on polyethylene grafted with Au nanoparticles," Nuclear Instruments and Methods in Physics Research B, vol. 272, pp. 391-395, 2011.

[8] O. Kubová, V. Švorčík, J. Heitz et al., "Characterization and cytocompatibility of carbon layers prepared by photoinduced chemical vapor deposition," Thin Solid Films, vol. 515, no. 17, pp. 6765-6772, 2007.

[9] P. Slepička, S. Trostová, N. Slepičková Kasálkova, Z. Kolská, P. Sajdl, and V. Švorčík, "Surface modification of biopolymers by argon plasma and thermal treatment," Plasma Processes and Polymers, vol. 9, no. 2, pp. 197-206, 2012.

[10] V. Švorčík, N. Kasálková, P. Slepička et al., "Cytocompatibility of Ar+ plasma treated and Au nanoparticle-grafted PE," Nuclear Instruments and Methods in Physics Research B, vol. 267, no. 11, pp. 1904-1910, 2009.

[11] N. Kasálková, Z. Makajová, M. Pařízek et al., "Cell adhesion and proliferation on plasma-treated and poly(ethylene glycol)-grafted polyethylene," Journal of Adhesion Science and Technology, vol. 24, no. 4, pp. 743-754, 2010.

[12] C. Oehr, "Plasma surface modification of polymers for biomedical use," Nuclear Instruments and Methods in Physics Research B, vol. 208, no. 1-4, pp. 40-47, 2003.
[13] B. M. P. Ferreira, L. M. P. Pinheiro, P. A. P. Nascente, and E. A. R. Duek, "Plasma surface treatments of poly(l-lactic acid) (PLLA) and poly(hydroxybutyrate-co-hydroxyvalerate) (PHBV)," Materials Science and Engineering C, vol. 29, no. 3, pp. 806-813, 2009.

[14] J. Meichsner, M. Nitschke, R. Rochotzki, and M. Zeuner, "Fundamental investigations in plasma modification of polymers," Surface and Coatings Technology, vol. 74-75, part 1, pp. 227-231, 1995.

[15] A. Řezníčková, Z. Kolská, V. Hnatowicz, P. Stopka, and V. Švorčík, "Comparison of glow argon plasma-induced surface changes of thermoplastic polymers," Nuclear Instruments and Methods in Physics Research B, vol. 269, no. 2, pp. 83-88, 2011.

[16] E. T. Kang and K. G. Neoh, Encyclopedia of Polymer Science and Technology, John Wiley \& Sons, 2009.

[17] L. Bačáková, V. Mareš, M. G. Bottone, C. Pellicciari, V. Lisá, and V. Švorčík, "Fluorine ion-implanted polystyrene improves growth and viability of vascular smooth muscle cells in culture," Journal of Biomedical Materials Research, vol. 49, no. 3, pp. 369-379, 2000.

[18] R. Morent, N. De Geyter, T. Desmet, P. Dubruel, and C. Leys, "Plasma surface modification of biodegradable polymers: a review," Plasma Processes and Polymers, vol. 8, no. 3, pp. 171190, 2011.

[19] R. P. Gandhiraman, M. K. Muniyappa, M. Dudek et al., "Interaction of Plasma deposited HMDSO-based coatings with Fibrinogen and human blood plasma: the correlation between bulk plasma, surface characteristics and biomolecule interaction," Plasma Processes and Polymers, vol. 7, no. 5, pp. 411-421, 2010.

[20] R. Förch, Z. Zhang, and W. Knoll, "Soft plasma treated surfaces: tailoring of structure and properties for biomaterial applications," Plasma Processes and Polymers, vol. 2, no. 5, pp. 351-372, 2005.

[21] R. D. Mundo, R. Gristina, E. Sardella et al., "Micro-/ nanoscale structuring of cell-culture substrates with fluorocarbon plasmas," Plasma Processes and Polymers, vol. 7, no. 3-4, pp. 212-223, 2010.

[22] E. Sardella, P. Favia, R. Gristina, M. Nardulli, and R. d'Agostino, "Plasma-aided micro- and nanopatterning processes for biomedical applications," Plasma Processes and Polymers, vol. 3, no. 6-7, pp. 456-469, 2006.

[23] E. T. Kang and Y. Zhang, "Surface modification of fluoropolymers via molecular design," Advanced Materials, vol. 12, no. 20, pp. 1481-1494, 2000.

[24] Y. S. Lin, S. S. Wang, T. W. Chung et al., "Growth of endothelial cells on different concentrations of Gly-Arg-GlyAsp photochemically grafted in polyethylene glycol modified polyurethane," Artificial Organs, vol. 25, no. 8, pp. 617-621, 2001.

[25] V. Švorčík, V. Hnatowicz, P. Stopka et al., "Amino acids grafting of $\mathrm{Ar}^{+}$ions modified PE," Radiation Physics and Chemistry, vol. 60, no. 1-2, pp. 89-93, 2001.

[26] J. G. Meinhart, M. Deutsch, T. Fischlein, N. Howanietz, A. Fröschl, and P. Zilla, "Clinical autologous in vitro endothelialization of 153 infrainguinal ePTFE grafts," Annals of Thoracic Surgery, vol. 71, no. 5, pp. 327-331, 2001.

[27] A. Rademacher, M. Paulitschke, R. Meyer, and R. Hetzer, "Endothelialization of PTFE vascular grafts under flow induces significant cell changes," International Journal of Artificial Organs, vol. 24, no. 4, pp. 235-242, 2001. 
[28] J. Heitz, T. Gumpenberger, H. Kahr, and C. Romanin, "Adhesion and proliferation of human vascular cells on UV-lightmodified polymers," Biotechnology and Applied Biochemistry, vol. 39, no. 1, pp. 59-69, 2004.

[29] V. Švorčík, K. Ročková, E. Ratajová et al., "Cell proliferation on UV-excimer lamp modified and grafted polytetrafluoroethylene," Nuclear Instruments and Methods in Physics Research B, vol. 217, no. 2, pp. 307-313, 2004.

[30] T. Gumpenberger, J. Heitz, D. Bäuerle et al., "Adhesion and proliferation of human endothelial cells on photochemically modified polytetrafluoroethylene," Biomaterials, vol. 24, no. 28, pp. 5139-5144, 2003.

[31] J. Heitz, T. Gumpenberger, N. Huber et al., "Optical method for improving the adhesion of biological cells on polymer surfaces," Austrian Patent No. 411220B, 2003.

[32] D. Bäuerle, Laser Processing and Chemistry, Springer, Heidelberg, Germany, 3rd edition, 2000.

[33] S. Lee, J. Kim, T. J. Park et al., "The effects of the physical properties of culture substrates on the growth and differentiation of human embryonic stem cells," Biomaterials, vol. 32, no. 34, pp. 8816-8829, 2011.

[34] H. Thissen, J. P. Hayes, P. Kingshott, G. Johnson, E. Harvey, and H. J. Griesser, "Nanometer thickness laser ablation for spatial control of cell attachment," Smart Materials and Structures, vol. 11, no. 5, pp. 792-799, 2002.

[35] A. Ohl and K. Schröder, "Plasma-induced chemical micropatterning for cell culturing applications: a brief review," Surface and Coatings Technology, vol. 116-119, pp. 820-830, 1999.

[36] T. K. Markkula, J. A. Hunt, F. R. Pu, and R. L. Williams, "Surface chemical derivatization of plasma-treated PET and PTFE," Surface and Interface Analysis, vol. 34, no. 1, pp. 583$587,2002$.

[37] B. Zhu, Q. Lu, J. Yin, J. Hu, and Z. Wang, "Effects of lasermodified polystyrene substrate on $\mathrm{CHO}$ cell growth and alignment," Journal of Biomedical Materials Research B, vol. 70, no. 1, pp. 43-48, 2004.

[38] X. Wang, C. A. Ohlin, Q. Lu, and J. Hu, "Influence of physicochemical properties of laser-modified polystyrene on bovine serum albumin adsorption and rat C6 glioma cell behavior," Journal of Biomedical Materials Research A, vol. 78, no. 4, pp. 746-754, 2006.

[39] C. Xu, F. Yang, S. Wang, and S. Ramakrishna, "In vitro study of human vascular endothelial cell function on materials with various surface roughness," Journal of Biomedical Materials Research A, vol. 71, no. 1, pp. 154-161, 2004.

[40] M. Arnold, E. A. Cavalcanti-Adam, R. Glass et al., "Activation of integrin function by nanopatterned adhesive interfaces," ChemPhysChem, vol. 5, no. 3, pp. 383-388, 2004.

[41] A. Thapa, T. J. Webster, and K. M. Haberstroh, "Polymers with nano-dimensional surface features enhance bladder smooth muscle cell adhesion," Journal of Biomedical Materials Research A, vol. 67, no. 4, pp. 1374-1383, 2003.

[42] M. J. Dalby, N. Gadegaard, R. Tare et al., "The control of human mesenchymal cell differentiation using nanoscale symmetry and disorder," Nature Materials, vol. 6, no. 12, pp. 997-1003, 2007.

[43] R. G. Flemming, C. J. Murphy, G. A. Abrams, S. L. Goodman, and P. F. Nealey, "Effects of synthetic micro- and nanostructured surfaces on cell behavior," Biomaterials, vol. 20, no. 6, pp. 573-588, 1999.
[44] R. Kemkemer, S. Jungbauer, D. Kaufmann, and H. Gruler, "Cell orientation by a microgrooved substrate can be predicted by automatic control theory," Biophysical Journal, vol. 90, no. 12, pp. 4701-4711, 2006.

[45] F. J. O'Brien, "Biomaterials and scaffolds for tissue engineering," Materials Today, vol. 14, no. 11, pp. 32-39, 2011.

[46] J. Jagur-Grodzinski, "Polymers for tissue engineering, medical devices, and regenerative medicine. Concise general review of recent studies," Polymers for Advanced Technologies, vol. 17, no. 6, pp. 395-418, 2006.

[47] M. T. Khorasani, H. Mirzadeh, and S. Irani, "Plasma surface modification of poly (l-lactic acid) and poly (lactic-coglycolic acid) films for improvement of nerve cells adhesion," Radiation Physics and Chemistry, vol. 77, no. 3, pp. 280-287, 2008.

[48] Y. Wan, J. Yang, J. Yang, J. Bei, and S. Wang, "Cell adhesion on gaseous plasma modified poly-(L-lactide) surface under shear stress field," Biomaterials, vol. 24, no. 21, pp. 37573764, 2003.

[49] L. Bačáková, E. Filová, F. Rypáček, V. Švorčík, and V. Starý, "Cell adhesion on artificial materials for tissue engineering," Physiological Research, vol. 53, no. 1, pp. 35-45, 2004.

[50] K. Anselme, A. Ponche, and M. Bigerelle, "Relative influence of surface topography and surface chemistry on cell response to bone implant materials. Part 2: biological aspects," Journal of Engineering in Medicine, vol. 224, no. 12, pp. 1487-1507, 2010.

[51] S. K. Sahoo and V. Labhasetwar, "Nanotech approaches to drug delivery and imaging," Drug Discovery Today, vol. 8, no. 24, pp. 1112-1120, 2003.

[52] H. Muguruma, "Plasma-polymerized films for biochip design,” Plasma Processes and Polymers, vol. 7, no. 2, pp. 151$162,2010$.

[53] F. Brétangol, A. Valsesia, G. Ceccone et al., "Surface functionalization and patterning techniques to design interfaces for biomedical and biosensor applications," Plasma Processes and Polymers, vol. 3, no. 6-7, pp. 443-455, 2006.

[54] Y. Yin, N. J. Nosworthy, B. Gong et al., "Plasma polymer surfaces compatible with a CMOS process for direct covalent enzyme immobilization," Plasma Processes and Polymers, vol. 6, no. 1, pp. 68-75, 2009.

[55] P. Heyse, A. Van Hoeck, M. B. J. Roeffaers et al., "Exploration of atmospheric pressure plasma nanofilm technology for straightforward bio-active coating deposition: enzymes, plasmas and polymers, an elegant synergy," Plasma Processes and Polymers, vol. 8, no. 10, pp. 965-974, 2011.

[56] G. Fridman, G. Friedman, A. Gutsol, A. B. Shekhter, V. N. Vasilets, and A. Fridman, "Applied plasma medicine," Plasma Processes and Polymers, vol. 5, no. 6, pp. 503-533, 2008.

[57] Y. W. Jun, J. T. Jang, and J. Cheon, "Magnetic nanoparticle assisted molecular MR imaging," Advances in Experimental Medicine and Biology, vol. 620, pp. 85-106, 2007.

[58] M. R. Lorenz, V. Holzapfel, A. Musyanovych et al., "Uptake of functionalized, fluorescent-labeled polymeric particles in different cell lines and stem cells," Biomaterials, vol. 27, no. 14, pp. 2820-2828, 2006.

[59] J. Rejman, V. Oberle, I. S. Zuhorn, and D. Hoekstra, "Sizedependent internalization of particles via the pathways of clathrin-and caveolae-mediated endocytosis," Biochemical Journal, vol. 377, no. 1, pp. 159-169, 2004.

[60] M. I. Santos, K. Tuzlakoglu, S. Fuchs et al., "Endothelial cell colonization and angiogenic potential of combined nanoand micro-fibrous scaffolds for bone tissue engineering," Biomaterials, vol. 29, no. 32, pp. 4306-4313, 2008. 
[61] A. Wang, Q. Ao, Y. Wei et al., "Physical properties and biocompatibility of a porous chitosan-based fiber-reinforced conduit for nerve regeneration," Biotechnology Letters, vol. 29, no. 11, pp. 1697-1702, 2007.

[62] G. S. Sailaja, P. Ramesh, T. V. Kumary, and H. K. Varma, "Human osteosarcoma cell adhesion behaviour on hydroxyapatite integrated chitosan-poly(acrylic acid) polyelectrolyte complex," Acta Biomaterialia, vol. 2, no. 6, pp. 651-657, 2006.

[63] M. O. Montjovent, S. Mark, L. Mathieu et al., "Human fetal bone cells associated with ceramic reinforced PLA scaffolds for tissue engineering," Bone, vol. 42, no. 3, pp. 554-564, 2008.

[64] C. Y. Hsieh, S. P. Tsai, D. M. Wang, Y. N. Chang, and H. J. Hsieh, "Preparation of $\gamma$-PGA/chitosan composite tissue engineering matrices," Biomaterials, vol. 26, no. 28, pp. 56175623, 2005.

[65] G. Wang and H. Uludag, "Recent developments in nanoparticle-based drug delivery and targeting systems with emphasis on protein-based nanoparticles," Expert Opinion on Drug Delivery, vol. 5, no. 5, pp. 499-515, 2008.

[66] P. K. Jain, X. Huang, I. H. El-Sayed, and M. A. El-Sayed, "Noble metals on the nanoscale: optical and photothermal properties and some applications in imaging, sensing, biology, and medicine," Accounts of Chemical Research, vol. 41, no. 12, pp. 1578-1586, 2008.

[67] R. Shukla, V. Bansal, M. Chaudhary, A. Basu, R. R. Bhonde, and M. Sastry, "Biocompatibility of gold nanoparticles and their endocytotic fate inside the cellular compartment: a microscopic overview," Langmuir, vol. 21, no. 23, pp. 10644 10654, 2005.

[68] M. Hulander, J. Hong, M. Andersson et al., "Blood interactions with noble metals: coagulation and immune complement activation," ACS Applied Materials \& Interfaces, vol. 1, no. 5, pp. 1053-1062, 2009.

[69] M. Giersig and P. Mulvaney, "Preparation of ordered colloid monolayers by electrophoretic deposition," Langmuir, vol. 9, no. 12, pp. 3408-3413, 1993.

[70] G. A. DeVries, M. Brunnbauer, Y. Hu et al., "Divalent metal nanoparticles," Science, vol. 315, no. 5810, pp. 358-361, 2007.

[71] R. A. Sperling, P. Rivera Gil, F. Zhang, M. Zanella, and W. J. Parak, "Biological applications of gold nanoparticles," Chemical Society Reviews, vol. 37, no. 9, pp. 1896-1908, 2008.

[72] N. Turner, M. Armitage, R. Butler, and G. Ireland, "An in vitro model to evaluate cell adhesion to metals used in implantation shows significant differences between palladium and gold or platinum," Cell Biology International, vol. 28, no. 7, pp. 541-547, 2004.

[73] S. Eustis and M. A. El-Sayed, "Why gold nanoparticles are more precious than pretty gold: noble metal surface plasmon resonance and its enhancement of the radiative and nonradiative properties of nanocrystals of different shapes," Chemical Society Reviews, vol. 35, no. 3, pp. 209-217, 2006.

[74] J. A. Dahl, B. L. S. Maddux, and J. E. Hutchison, "Toward greener nanosynthesis," Chemical Reviews, vol. 107, no. 6, pp. 2228-2269, 2007.

[75] R. Bhattacharya, C. R. Patra, R. Verma, S. Kumar, P. R. Greipp, and P. Mukherjee, "Gold nanoparticles inhibit the proliferation of multiple myeloma cells," Advanced Materials, vol. 19, no. 5, pp. 711-716, 2007.

[76] P. Ghosh, G. Han, M. De, C. K. Kim, and V. M. Rotello, "Gold nanoparticles in delivery applications," Advanced Drug Delivery Reviews, vol. 60, no. 11, pp. 1307-1315, 2008.
[77] D. Pissuwan, S. M. Valenzuela, and M. B. Cortie, "Therapeutic possibilities of plasmonically heated gold nanoparticles," Trends in Biotechnology, vol. 24, no. 2, pp. 62-67, 2006.

[78] C. Harter, H. J. Salwender, A. Bach, G. Egerer, H. Goldschmidt, and A. D. Ho, "Catheter-related infection and thrombosis of the internal jugular vein in hematologiconcologic patients undergoing chemotherapy: a prospective comparison of silver-coated and uncoated catheters," Cancer, vol. 94, no. 1, pp. 245-251, 2002.

[79] Y. Pan, S. Neuss, A. Leifert et al., "Size-dependent cytotoxicity of gold nanoparticles," Small, vol. 3, no. 11, pp. 1941-1949, 2007.

[80] B. Alberts, A. Johnson, J. Lewis, M. Raff, K. Roberts, and P. Walter, Molecular Biology of The Cell, Garland Publishing, New York, NY, USA, 4th edition, 2002.

[81] V. Švorčík, V. Rybka, V. Hnatowicz, and L. Bačáková, "Polarity, resistivity and biocompatibility of polyethylene doped with carbon black," Journal of Materials Science Letters, vol. 14, no. 24, pp. 1723-1724, 1995.

[82] C. Morrison, R. Macnair, C. MacDonald, A. Wykman, I. Goldie, and M. H. Grant, "In vitro biocompatibility testing of polymers for orthopaedic implants using cultured fibroblasts and osteoblasts," Biomaterials, vol. 16, no. 13, pp. 987-992, 1995.

[83] V. Starý, L. Bačáková, J. Horník, and V. Chmelík, "Biocompatibility of the surface layer of pyrolytic graphite," Thin Solid Films, vol. 433, no. 1-2, pp. 191-198, 2003.

[84] V. Svorcík, K. Prosková, V. Hnatowicz, and A. Kluge, "Polyimide modified by irradiation with $\mathrm{C}+$ and $\mathrm{N}+$ ion beams," Polymer Degradation and Stability, vol. 65, no. 1, pp. 131-135, 1999.

[85] P. K. Chu, J. Y. Chen, L. P. Wang, and N. Hang, "Plasmasurface modification of biomaterials," Materials Science and Engineering Reports, vol. 36, no. 5-6, pp. 143-206, 2002.

[86] S. E. Rodil, R. Olivares, H. Arzate, and S. Muhl, "Properties of carbon films and their biocompatibility using in-vitro tests," Diamond and Related Materials, vol. 12, no. 3-7, pp. 931-937, 2003.

[87] J. D. Carey, R. D. Forrest, and S. R. P. Silva, "Origin of electric field enhancement in field emission from amorphous carbon thin films," Applied Physics Letters, vol. 78, no. 16, pp. 23392341, 2001.

[88] A. Alanazi, C. Nojiri, T. Kido et al., "Improved blood compatibility of DLC coated polymeric material," Artificial Organs, vol. 46, no. 4, pp. 440-443, 2000.

[89] P. Yang, S. C. H. Kwok, R. K. Y. Fu et al., "Structure and properties of annealed amorphous hydrogenated carbon (aC:H) films for biomedical applications," Surface and Coatings Technology, vol. 177-178, pp. 747-751, 2004.

[90] A. Schroeder, G. Francz, A. Bruinink, R. Hauert, J. Mayer, and E. Wintermantel, "Titanium containing amorphous hydrogenated carbon films (a-C:H/Ti): surface analysis and evaluation of cellular reactions using bone marrow cell cultures in vitro," Biomaterials, vol. 21, no. 5, pp. 449-456, 2000.

[91] F. Z. Cui and D. J. Li, "A review of investigations on biocompatibility of diamond-like carbon and carbon nitride films," Surface and Coatings Technology, vol. 131, no. 1-3, pp. 481-487, 2000.

[92] K. Ročková, V. Švorčík, L. Bačáková, B. Dvořánková, and J. Heitz, "Bio-compatibility of ion beam-modified and RGDgrafted polyethylene," Nuclear Instruments and Methods in Physics Research B, vol. 225, no. 3, pp. 275-279, 2004. 
[93] V. Kotál, V. Švorčík, P. Slepička et al., "Gold coating of poly(ethylene terephthalate) modified by argon plasma," Plasma Processes and Polymers, vol. 4, no. 1, pp. 69-76, 2007.

[94] V. Švorčík, V. Kotál, J. Siegel, P. Sajdl, A. Macková, and V. Hnatowicz, "Ablation and water etching of poly(ethylene) modified by argon plasma," Polymer Degradation and Stability, vol. 92, no. 9, pp. 1645-1649, 2007.

[95] Z. Chang and J. A. LaVerne, "Molecular hydrogen production in the radiolysis of high-density polyethylene," Journal of Physical Chemistry B, vol. 103, no. 39, pp. 8267-8271, 1999.

[96] Y. Susuki, K. Hojo, I. Okazaki et al., "Preparation and biological activities of a bivalent poly(ethylene glycol) hybrid containing an active site and its synergistic site of fibronectin," Chemical and Pharmaceutical Bulletin, vol. 50, no. 9, pp. 1229-1232, 2002.

[97] V. ŠvorčíK, K. Ročková, B. Dvořánková et al., "Cell adhesion on modified polyethylene," Journal of Materials Science, vol. 37, no. 6, pp. 1183-1188, 2002.

[98] R. L. Claugh, "High-energy radiation and polymers: a review of commercial processes and emerging applications," Nuclear Instruments and Methods in Physics Research B, vol. 185, no. 1-4, pp. 8-33, 2001.

[99] I. Simkiene, J. Sabataityte, G. J. Babonas, A. Reza, and J. Beinoras, "Self-organization of porphyrin structures on Si," Materials Science and Engineering C, vol. 26, no. 5-7, pp. 1007-1011, 2006.

[100] A. S. R. Koti and N. Periasamy, "Self-assembly of templatedirected J-aggregates of porphyrin," Chemistry of Materials, vol. 15, no. 2, pp. 369-371, 2003.

[101] A. Synytsya, V. Král, M. Blechová, and K. Volka, "Biolocalisation and photochemical properties of two novel macrocyclic photosensitisers: a spectroscopic study," Journal of Photochemistry and Photobiology B, vol. 74, no. 2-3, pp. 73-84, 2004.

[102] N. Morii, G. Kido, T. Konakahara, and H. Morii, "Molecular orientation of porphyrins accompanying the formation of chain-aligned DNA films," Biomacromolecules, vol. 6, no. 6, pp. 3259-3266, 2005.

[103] A. Synytsya, A. Synytsya, P. Blafková, V. Král, and K. Volka, "Interaction of meso-tetrakis(4-sulphonatophenyl)porphine with chitosan in aqueous solutions," Spectrochimica Acta A, vol. 66, no. 2, pp. 225-235, 2007.

[104] S. Sortino, A. Mazzaglia, L. Monsu Scolaro, F. M. Merlo, and M. T. Valveri Sciortino, "Nanoparticles of cationic amphiphilic cyclodextrins entangling anionic porphyrins as carrier-sensitizer system in photodynamic cancer therapy," Biomaterials, vol. 27, no. 23, pp. 4256-4265, 2006.

[105] V. Gulbinas, R. Karpicz, R. Augulis, and R. Rotomskis, "Exciton relaxation in nanotubular TPPS4 aggregates in water solution and in polymeric matrix," Chemical Physics, vol. 332, no. 2-3, pp. 255-261, 2007.

[106] N. M. Inada, A. R. da Silva, R. A. Jorge, J. Borecký, and A. E. Vercesi, "Irradiated cationic mesoporphyrin induces larger damage to isolated rat liver mitochondria than the anionic form," Archives of Biochemistry and Biophysics, vol. 457, no. 2, pp. 217-224, 2007.

[107] A. Synytsya, A. Synytsya, P. Blafková et al., "pH-controlled self-assembling of meso-tetrakis(4-sulfonatophenyl)porphyrin- chitosan complexes," Biomacromolecules, vol. 10, no. 5, pp. 1067-1076, 2009.

[108] L. Bacakova, L. Grausova, J. Vacik et al., "Improved adhesion and growth of human osteoblast-like MG 63 cells on biomaterials modified with carbon nanoparticles," Diamond and Related Materials, vol. 16, no. 12, pp. 2133-2140, 2007.
[109] S. Foley, C. Crowley, M. Smaihi et al., "Cellular localisation of a water-soluble fullerene derivative," Biochemical and Biophysical Research Communications, vol. 294, no. 1, pp. 116-119, 2002.

[110] H. Yamawaki and N. Iwai, "Cytotoxicity of water-soluble fullerene in vascular endothelial cells," American Journal of Physiology, vol. 290, no. 6, pp. C1495-C1502, 2006.

[111] Y. J. Tang, J. M. Ashcroft, D. Chen et al., "Charge-associated effects of fullerene derivatives on microbial structural integrity and central metabolism," Nano Letters, vol. 7, no. 3, pp. 754-760, 2007.

[112] E. Nakamura and H. Isobe, "Functionalized fullerenes in water. The first 10 years of their chemistry, biology, and nanoscience," Accounts of Chemical Research, vol. 36, no. 11, pp. 807-815, 2003.

[113] N. Levi, R. R. Hantgan, M. O. Lively, D. L. Carroll, and G. L. Prasad, "C60-fullerenes: detection of intracellular photoluminescence and lack of cytotoxic effects," Journal of Nanobiotechnology, vol. 4, article 14, 2006.

[114] R. L. Price, M. C. Waid, K. M. Haberstroh, and T. J. Webster, "Selective bone cell adhesion on formulations containing carbon nanofibers," Biomaterials, vol. 24, no. 11, pp. 18771887, 2003.

[115] G. Wei and P. X. Ma, "Structure and properties of nanohydroxyapatite/polymer composite scaffolds for bone tissue engineering," Biomaterials, vol. 25, no. 19, pp. 4749-4757, 2004.

[116] A. P. Marques, R. L. Reis, and J. A. Hunt, "The biocompatibility of novel starch-based polymers and composites: in vitro studies," Biomaterials, vol. 23, no. 6, pp. 1471-1478, 2002.

[117] R. Mikulíková, V. Švorčík, J. Náhlík, T. Sopuch, and P. Havelka, "Cytocompatibility of surface ground PE doped with calcium salt of 6-carboxycellulose," Cellulose, vol. 15, no. 3, pp. 473-479, 2008.

[118] G. Altankov, V. Thorn, T. Groth, K. Jankova, G. Jonsson, and M. Ulbricht, "Modulating the biocompatibility of polymer surfaces with poly(ethylene glycol): effect of fibronectin," Journal of Biomedical Materials Research, vol. 52, no. 1, pp. 219-230, 2000.

[119] L. Bačáková and V. Švorčík, "Cell colonization control by physical and chemical modification of materials," in Cell Growth Processes: New Research, D. Kimura, Ed., pp. 5-56, Nova Science Publishers, Hauppauge, NY, USA, 2008.

[120] M. Pařízek, N. Kasálková, L. Bačáková et al., "Improved adhesion, growth and maturation of vascular smooth muscle cells on polyethylene grafted with bioactive molecules and carbon particles," International Journal of Molecular Sciences, vol. 10, no. 10, pp. 4352-4374, 2009.

[121] V. Švorčík, K. Kolářová, P. Slepička, A. Macková, M. Novotná, and V. Hnatowicz, "Modification of surface properties of high and low density polyethylene by Ar plasma discharge," Polymer Degradation and Stability, vol. 91, no. 6, pp. 12191225, 2006.

[122] V. Švorčík, V. Kotál, P. Slepička et al., "Modification of surface properties of polyethylene by Ar plasma discharge," Nuclear Instruments and Methods in Physics Research B, vol. 244, no. 2, pp. 365-372, 2006.

[123] J. Heitz, V. Švorčík, L. Bačáková et al., "Cell adhesion on polytetrafluoroethylene modified by UV-irradiation in an ammonia atmosphere," Journal of Biomedical Materials Research A, vol. 67, no. 1, pp. 130-137, 2003.

[124] K. S. Kim, C. M. Ryu, C. S. Park, G. S. Sur, and C. E. Park, "Investigation of crystallinity effects on the surface of oxygen plasma treated low density polyethylene using X-ray 
photoelectron spectroscopy," Polymer, vol. 44, no. 20, pp. 6287-6295, 2003.

[125] L. Guo, N. Kawazoe, Y. Fan et al., "Chondrogenic differentiation of human mesenchymal stem cells on photoreactive polymer-modified surfaces," Biomaterials, vol. 29, no. 1, pp. 23-32, 2008.

[126] L. Bacáková, K. Walachová, V. Švorčík, and V. Hnatowicz, "Adhesion and proliferation of rat vascular smooth muscle cells (VSMC) on polyethylene implanted with $\mathrm{O}+$ and $\mathrm{C}+$ ions," Journal of Biomaterials Science Polymer Edition, vol. 12, no. 7, pp. 817-834, 2001.

[127] K. Prosková, V. Svorcík, V. Rybka, and V. Hnatowicz, "Selected degradation reactions in polyethylene irradiated with Ar+ and Xe+ ions," Radiation Physics and Chemistry, vol. 58, no. 2, pp. 153-156, 2000.

[128] V. Švorčík, K. Walachová, J. Heitz, T. Gumpenberger, and L. Bačáková, "Muscle cell adhesion on polytetrafluorethylene modified by UV irradiation," Journal of Materials Science Letters, vol. 20, no. 21, pp. 1941-1942, 2001. 

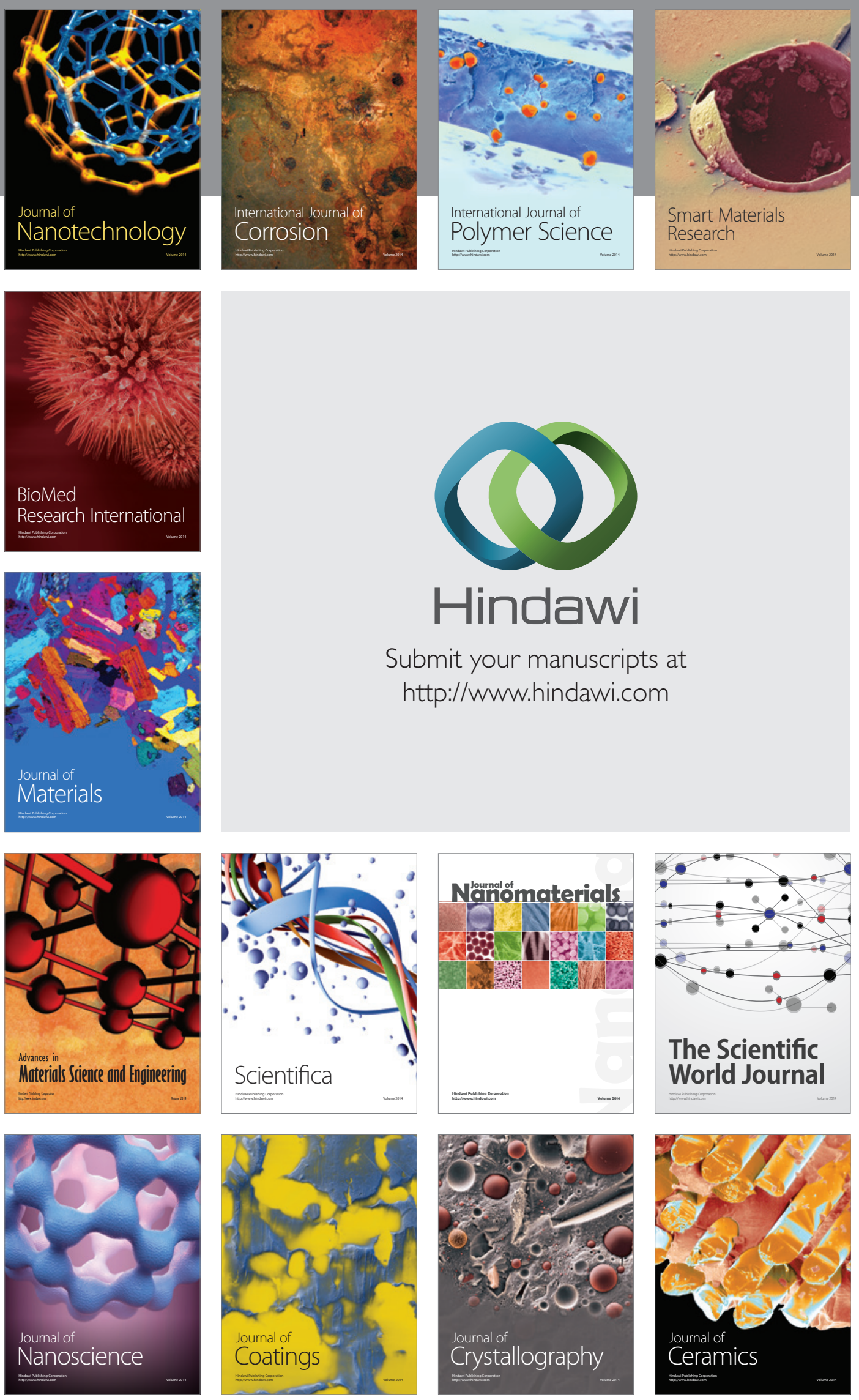

The Scientific World Journal

Submit your manuscripts at

http://www.hindawi.com

\section{World Journal}

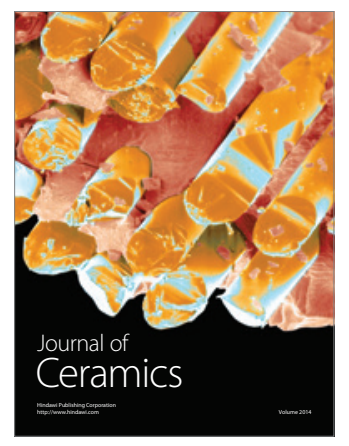

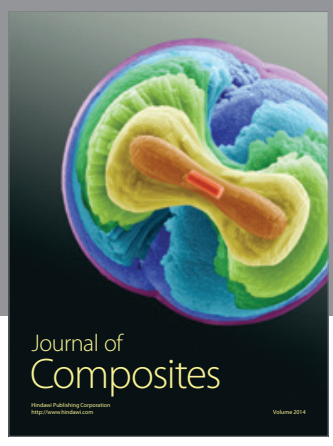
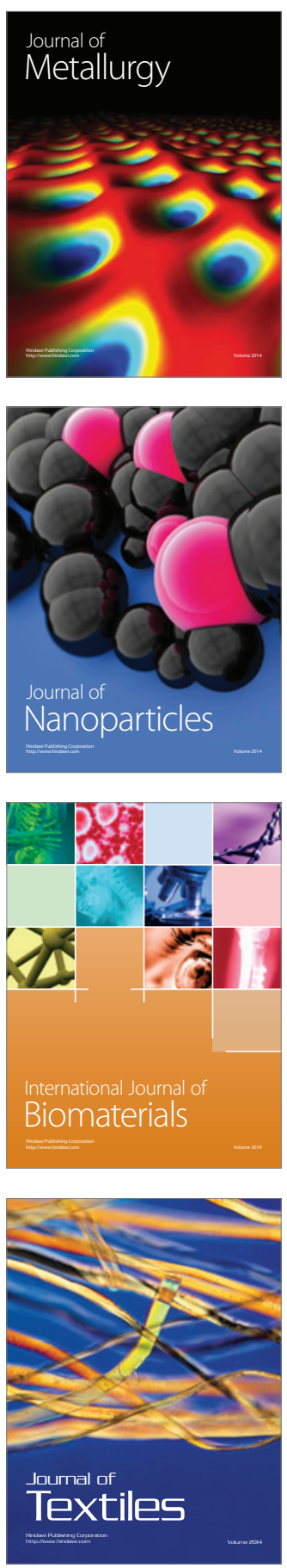